\title{
Energy and exergy analysis of acid gas removal processes in the LNG production chain
}

\author{
Laura A. Pellegrini, Giorgia De Guido*, Valentina Valentina \\ Dipartimento di Chimica, Materiali e Ingegneria Chimica “G. Natta”, Politecnico di Milano, Piazza Leonardo da Vinci 32, 20133, Milano, Italy
}

\section{A R T ICLE INFO}

\section{Keywords:}

Natural gas purification

Carbon dioxide

Activated-MDEA

Low-temperature distillation

Liquefaction

LNG

\begin{abstract}
A B S T R A C T
In the energy transition towards a zero-carbon energy sector, natural gas grows much faster than either oil or coal, since it is an environmentally-friendly fuel supported by the continuing expansion of LNG, increasing the availability of gas globally. In recent years, the substantial growth in the world energy demand has increased the interest in the exploitation of natural gas reservoirs previously deemed undesirable due to their high acid gas content. Existing technologies for natural gas purification, such as chemical absorption with alkanolamine solvents, may be not suitable for treating highly contaminated natural gas due to the required higher solvent circulation rate and, consequently, to the energy demand for solvent regeneration. Over the last decades attention has been devoted to the study and development of low-temperature $\mathrm{CO}_{2}$ removal processes. With these new technologies, $\mathrm{CO}_{2}$ is separated as a high-pressure liquid making it easier to be pumped underground for sequestration or utilization in Enhanced Oil Recovery (EOR) projects.

The aim of this work is to analyze natural gas purification technologies and liquefaction schemes for the production of LNG starting from the same acid natural gas stream. In particular, two $\mathrm{CO}_{2}$ removal technologies are considered to bring $\mathrm{CO}_{2}$ concentrations down to levels suitable for LNG production: the conventional chemical absorption technology with activated-MDEA (aMDEA) as solvent and the recently patented Dual Pressure Low-Temperature (DPLT) distillation technology. Different commercial technologies are taken into account for the liquefaction of the purified natural gas: Propane-Mixed Refrigerant (C3MR), Mixed Fluid Cascade (MFC), and Single Mixed Refrigerant (SMR). However, since these liquefaction processes are designed for a sweet gas obtained using a conventional acid gas removal technology, some adjustments have been made for their application to a low-temperature sweet gas. The choice to compare a conventional technology with a novel low-temperature one has been made to understand if the synergy between a $\mathrm{CO}_{2}$ removal technology operated at low-temperature and the downstream liquefaction process is advantageous, despite the need for refrigeration also in the $\mathrm{CO}_{2}$ removal step.

The different process schemes resulting from the combination of the two $\mathrm{CO}_{2}$ removal technologies with the liquefaction ones have been simulated in Aspen HYSYS ${ }^{\circledR}$ V10 and their performances are assessed and compared by means of energy and exergy analyses, respectively based on the "net equivalent methane" approach and on the exergy efficiency concept.

Results suggest that, although the aMDEA absorption process and the DPLT distillation one with downstream separation of NGLs recovery have about the same specific energy consumption when applied to the natural gas stream taken into account in this work considering the $\mathrm{CO}_{2}$ removal step only, the overall process (including the liquefaction of the purified natural gas stream) involving the DPLT distillation technology is characterized by lower consumptions and a higher exergy efficiency.
\end{abstract}

\section{Introduction}

According to the International Energy Agency (U.S.Energy Information Administration (EIA), 2017), fossil fuels will still account for $77 \%$ of energy use in 2040 and natural gas (NG) is projected to be the fastest growing fuel source. Despite its abundant availability and its cleaner-burning characteristics, transportation of natural gas has been a major obstacle in natural gas marketing. It is not practical and economical to transport natural gas by vehicles or ships due to the large volume of natural gas at ambient temperature and at atmospheric pressure. Transportation of gas using pipelines is economically justifiable and technically feasible up to a distance of approximately $3500 \mathrm{~km}$ for onshore operations and $1500 \mathrm{~km}$ for offshore operations (Pettersen,

\footnotetext{
* Corresponding author.

Email address: giorgia.deguido@polimi.it (G. De Guido)
} 
2012). At distances greater than these, transporting natural gas in its liquefied form (Liquefied Natural Gas or LNG) is usually preferred (Pellegrini et al., 2014). In this state, the volume of natural gas is reduced by a factor of more than 600 .

In order to produce LNG, natural gas must be purified from its contaminants to avoid several problems in the downstream liquefaction process (Table 1). Then, the purified raw natural gas (sweet and dry gas) is fed to the liquefaction process in order to obtain a condensed natural gas at atmospheric pressure by reducing its temperature down to approximately $-160^{\circ} \mathrm{C}$.

The development of contaminated natural gas fields has become progressively crucial to keep up with the increasing demand for natural gas. In some gas fields (Table 2), the concentration of $\mathrm{CO}_{2}$ can exceed $70 \%$ (Darman and Harun, 2006; De Guido et al., 2018). When dealing with such acid natural gas reservoirs, environmental concerns arise, particularly regarding the amount of acid gases that need to be rejected as by-product or waste. Releasing a substantial amount of acid gas to the atmosphere is not an environmentally-friendly solution. Worldwide perceptions on climate change are pressuring energy companies to adopt global best practices to reduce carbon emissions, such as through $\mathrm{CO}_{2}$ geo-sequestration (Maqsood et al., 2014).

The most common technology used in the Acid Gas Removal Unit (AGRU) of LNG production plants, also used for the upgrading of biogas to biomethane (Pellegrini et al., 2015a), is amine absorption coupled with its regeneration column. This process can be very expensive if applied to low-quality gas fields. Both capital and operating costs increase proportionally with the concentration of acid gases to be removed. In addition, this technology removes $\mathrm{CO}_{2}$ at near ambient pressure and, hence, requires substantial compression to reach the levels needed for geo-sequestration (Northrop and Valencia, 2009).

LNG producers need new solutions to allow the profitable exploitation of reserves with a high acid gas content. Provided solutions must be able to remove acid gases and other impurities to meet commercial specifications, decreasing the overall production costs. In the last

Table 1

Typical composition of natural gas, LNG, and reasons for the removal of the contaminants (Shimekit and Mukhtar, 2012; Mokhatab et al., 2013; Kidnay et al., 2011; Association, 2013).

\begin{tabular}{llll}
\hline Component & Molar fraction & Reasons for contaminants removal \\
\hline & Raw NG & LNG & \\
\hline $\mathrm{CH}_{4}$ & $70-90 \%$ & $85-97 \%$ & - \\
$\mathrm{C}_{2} \mathrm{H}_{6}$ & $0-20 \%$ & $<4 \%$ & Product specifications \\
$\mathrm{C}_{3} \mathrm{H}_{8}, \mathrm{n}-$ & $0-20 \%$ & $<2 \%$ & \\
$\mathrm{C}_{4} \mathrm{H}_{10}$ & & & \\
$\mathrm{C}_{5} \mathrm{H}_{12}$, & $0-20 \%$ & $<0.02 \%$ & Solid formation during liquefaction and \\
$\mathrm{C}_{6} \mathrm{H}_{14}$ & $0-5 \%$ & $<0.1 \mathrm{ppm}$ & potential equipment damage \\
$\mathrm{H}_{2} \mathrm{O}$ & $0-8 \%$ & $<50 \mathrm{ppm}$ & \\
$\mathrm{CO}_{2}$ & $0-5 \%$ & $<1 \mathrm{ppm}$ & \\
$\mathrm{H}_{2} \mathrm{~S}$ & $0-5 \%$ & $<1 \mathrm{ppt}$ & Formation of amalgamates with \\
$\mathrm{Hg}$ & & & $\begin{array}{l}\text { aluminum in heat exchangers resulting in } \\
\text { a mechanical failure and gas leakage }\end{array}$ \\
& & &
\end{tabular}

Table 2

Some natural gas reserves with high acid gases contents.

\begin{tabular}{lll}
\hline Gas Field & Location & Acid gas contents \\
\hline Natuna (Bagirov et al., 2015) & Indonesia & $>70 \% \mathrm{CO}_{2}$ \\
K5 (Darman and Harun, 2006) & Malaysia & $70 \% \mathrm{CO}_{2}$ \\
LaBarge (Parker et al., 2011) & U.S. & $65 \% \mathrm{CO}_{2}$ \\
Kapuni (Rojey and Jaffret, 1997) & New Zealand & $43.8 \% \mathrm{CO}_{2}$ \\
Uch (Rojey and Jaffret, 1997) & Pakistan & $46.2 \% \mathrm{CO}_{2}$ \\
Bearberry (Scherbinin, 2012) & Canada & $90 \% \mathrm{H}_{2} \mathrm{~S}$ \\
Shah (Boschee, 2014) & UAE & $23 \% \mathrm{H}_{2} \mathrm{~S}$ and $10 \% \mathrm{CO}_{2}$ \\
\hline
\end{tabular}

decades attention has been devoted to study and develop low-temperature or cryogenic $\mathrm{CO}_{2}$ removal processes. These new technologies can be classified into two main groups depending whether the formation of solid $\mathrm{CO}_{2}$ is allowed or not. For example, the $\mathrm{CFZ}^{\mathrm{TM}}$ (Controlled-Freeze-Zone ${ }^{\mathrm{TM}}$ ) process developed by Exxon Mobil (Haut and Thomas, 1989; Valencia and Denton, 1985; Valencia and Victory, 1990), the Cryocell (Amin et al., 2005; Hart and Gnanendran, 2009), and the Cryo Pur (Clodic and Younes, 2003) processes allow dry ice to form in a dedicated section. On the contrary, other processes such as Ryan-Holmes (Holmes and Ryan, 1982a; Holmes and Ryan, 1982b; Holmes et al., 1983), Sprex ${ }^{\circledR}$ (Lallemand et al., 2005; Lallemand et al., 2014), and the Dual Pressure Low-Temperature (DPLT) distillation (Pellegrini, 2014) process avoid the formation of solid $\mathrm{CO}_{2}$.

In general, the low-temperature (or cryogenic) natural gas purification technologies produce a methane stream at high purity and at a low temperature level. Thus, they are suitable for LNG production. In addition, distillation-based low-temperature methods can capture $\mathrm{CO}_{2}$ in a high-pressure liquid form, making it relatively easy to be pumped underground for sequestration (Mazzoccoli et al., 2013) or to be used for Enhanced Oil Recovery. Hence, it is more beneficial considering the possibility of avoiding the release of a substantial amount of acid gases as waste.

The aim of this work is to compare the performances of two $\mathrm{CO}_{2}$ removal technologies, i.e. the conventional chemical absorption and a low-temperature distillation process when applied to LNG production. It is necessary to understand if the synergy between the low-temperature process and the natural gas liquefaction process can be advantageous, due to the low-temperature level of the sweet gas stream obtained from the AGRU, despite the need for refrigeration at low temperature (De Guido et al., 2015). In this work, the performances of the different processes are evaluated and compared by means of energy (net equivalent methane) and exergy analyses.

The outline of the work is depicted in Fig. 1. Initially, the conventional chemical absorption process for acid gas removal is compared to the low-temperature one. After that, various liquefaction cycles are compared to find the least energy consuming and most exergy efficient scheme. In the end, the whole schemes of LNG production for the two cases are compared.

In the natural gas and petroleum industries, solvents that are widely used for chemical absorption of acid gases are the alkanolamines. The aMDEA (activated-MDEA) process has been the major innovation within the gas treating industry (Alvis et al., 2012). In this process, MDEA's capability for $\mathrm{CO}_{2}$ removal is enhanced by adding proprietary additives in various proportions to achieve the desired removal target. Some advantages of using MDEA and the formulated MDEA as solvents are explained in the literature (Kohl and Nielsen, 1997). Piperazine (PZ) is the most applied promoter for $\mathrm{CO}_{2}$ removal operation since it is highly reactive with $\mathrm{CO}_{2}$ (Alvis et al., 2012). This will reduce the amount of solvent recirculation rate. For this work, the MDEA + PZ blend (aMDEA) is used as solvent.

Among several low-temperature acid gas removal technologies, the DPLT distillation process has been recently patented (Pellegrini, 2014) and a pilot plant is now in operation (Pellegrini et al., 2015b; Pellegrini et al., 2016). It allows the separation of $\mathrm{CO}_{2}$ from methane and heavier hydrocarbons without the formation of solid $\mathrm{CO}_{2}$. The natural gas stream is treated in a dual pressure distillation unit: the high-pressure column for the $\mathrm{CO}_{2}$ bulk removal and the low-pressure column where the gas is purified in order to comply with the desired LNG specifications. Previous studies have compared different low-temperature technologies proving the better performances of the DPLT distillation process (Pellegrini et al., 2017a).

The natural gas liquefaction process plays a key role in LNG plants in terms of cost and operational importance. Therefore, in selecting the most appropriate technology, both technical and economic considera- 


\begin{tabular}{|c|c|c|}
\hline \multicolumn{3}{|c|}{ Comparison of Acid Gas Removal Units (AGRUs) } \\
\hline \multicolumn{2}{|c|}{$\begin{array}{c}\text { Conventional amine absorption } \\
\text { (aMDEA) }\end{array}$} & $\begin{array}{c}\text { New Dual Pressure Low-Temperature } \\
\text { (DPLT) distillation technology }\end{array}$ \\
\hline \multicolumn{3}{|c|}{ Comparison of liquefaction technologies } \\
\hline $\begin{array}{l}\text { Propane-Mixed Refrigerant } \\
\text { (C3MR) }\end{array}$ & $\begin{array}{c}\text { Mixed Fluid Cascade } \\
\text { (MFC) }\end{array}$ & $\begin{array}{c}\text { Single Mixed Refrigerant } \\
\text { (SMR) }\end{array}$ \\
\hline \multicolumn{3}{|c|}{ Comparison of overall LNG production plants } \\
\hline aMDEA+Liquefac & & $\mathrm{LT}+$ Liquefaction \\
\hline
\end{tabular}

Fig. 1. Block diagram illustrating the outline of the work.

tions must be addressed. Since natural gas is a mixture, during the cooling process, the phase change occurs at a non-constant temperature. A mixed refrigerant is applied in order to obtain a cooling curve as near as possible to the one of natural gas (Smith, 2005), however avoiding temperature cross between the two fluids. The minimum temperature approach is usually $3-5^{\circ} \mathrm{C}$ (Khan et al., 2015). In this work, three licensed and commercially well-known natural gas liquefaction technologies operating with mixed refrigerants are considered. The propane precooled mixed refrigerant (C3MR) by Air Products and Chemicals Inc. (APCI) is the most widely used process (Mokhatab et al., 2013; Venkatarathnam and Timmerhaus, 2008). A cascade process operating with mixtures, Mixed Fluid Cascade (MFC), has been recently developed by Statoil and Linde (Mokhatab et al., 2013; Venkatarathnam and Timmerhaus, 2008). Both processes are suitable for onshore operations. Another process, Single Mixed Refrigerant (SMR) by Black \& Veatch (PRICO process (Mokhatab et al., 2013; Venkatarathnam and Timmerhaus, 2008)) is the most used liquefaction cycle for offshore operations.

\section{Methods}

This section deals with the energy and exergy analyses that have been carried out to compare both AGR processes and the three different liquefaction processes. Table 3 summarizes the equations used in the energy and exergy analyses.

Table 3

Summary of equations for the energy (net equivalent methane) and for the exergy analyses.

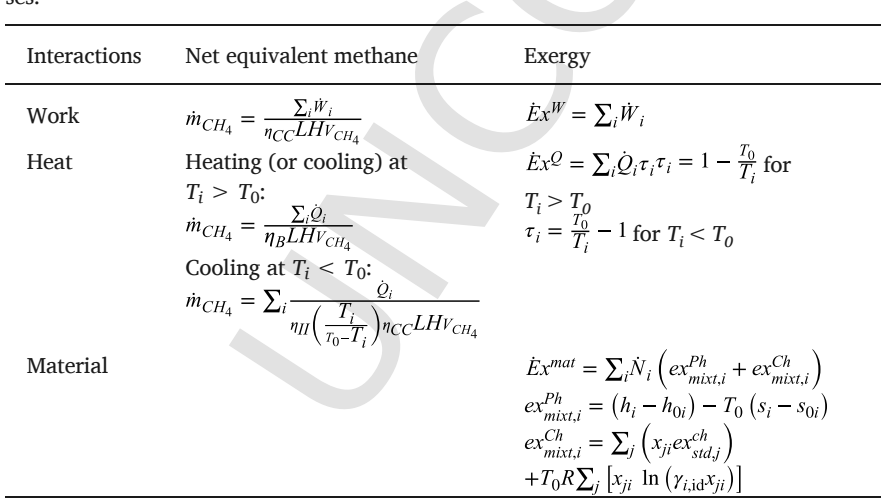

\subsection{Energy analysis}

The energy analysis is based on the "net equivalent methane" method (De Guido et al., 2018; Pellegrini et al., 2015c; Pellegrini et al., 2017b), where all the energy interactions between the analyzed process and the external environment are converted into the equivalent amount of methane that is required to provide such interactions. The term interaction is used since energy can be consumed or produced by the process, i.e. entering the system or released from the system. Heat that is released (produced) from the system is considered as saving whenever it is easily recoverable (at high temperature level, i.e. above $147^{\circ} \mathrm{C}$, where the low-pressure steam at 3.5 bar can be produced). By using the same basis for the various types of energy, the "net equivalent methane" method enables a fair comparison among different processes. The reader can refer to other literature works for further details (De Guido et al., 2018; Pellegrini et al., 2015c; Pellegrini et al., 2017b). The parameter values used in the "net equivalent methane" analysis are summarized in Table 4. The processes studied in the present work have been compared by evaluating the "specific equivalent methane consumption" (SMC) defined as:

SMC

$=\frac{\sum \text { Methane equivalent consumption }}{\sum \text { Methane in the inlet Acid NG }}\left[\frac{\mathrm{kg}_{\mathrm{CH}_{4} \text {,eq. }}}{\mathrm{kg}_{\mathrm{CH}_{4}, \text { in }}}\right]$

\subsection{Exergy analysis}

The maximum amount of work that can be obtained from a given form of energy using the environmental parameters as reference is called exergy (Kotas, 2013). The exergy analysis permits many of the shortcomings of the energy analysis to be overcome. For example, the energy analysis does not recognize the difference between cooling below and above ambient temperature. The required exergy (work) to cool a process stream down to one degree below the initial temperature is always larger than the necessary exergy (heat) to heat the same

Table 4

Values of parameters used in the "net equivalent methane" analysis.

\begin{tabular}{ll}
\hline Parameters & Values \\
\hline$L H V_{C H_{4}}[\mathrm{~kJ} / \mathrm{kg}]$ & 50000 \\
$\eta_{C C}$ Kehlhofer et al. (2009) & 0.55 \\
$\eta_{I I}$ (DITEC Università degli Studi di Genova) & 0.60 \\
$\eta_{B}$ CleaverBrooks Inc. and Boile (2011) & 0.80 \\
\hline
\end{tabular}


process stream up to one degree above the initial temperature, and this difference increases further away from reference conditions (Marmolejo-Correa and Gundersen, 2012). Thus, the exergy associated with an energy quantity is a quantitative assessment of its usefulness or quality. Exergy analysis further validates the result of energy analysis without introducing the assumptions necessary for the "net equivalent methane" method.

In this work, exergy related to work (electricity), heat, and material streams are considered. Numerically, exergy for work interactions ( $\dot{E} x^{W}$ in Table 3) is equal to the work as energy (Kotas, 2013). Energy consumption is counted as exergy expenses and energy production as exergy saving. The exergy for the heat interactions ( $E_{x} Q$ in Table 3), removed or supplied, can be evaluated from the definition of the Carnot factor, $\tau_{i}$, which is based on both the temperatures of the environment, $T_{0}$, and of the surfaces, $T_{i}$, at which the heat transfer of the heat flow $Q_{i}$ occurs (Kotas, 2013). Exergy of heat that is removed (produced) from the system is considered as exergy saving.

The exergy of material streams ( $\dot{E} x^{\text {mat }}$ in Table 3) is evaluated using the methodology explained in the literature (Kotas, 2013). Neglecting the effects due to magnetism, surface tension, nuclear reactions, kinetic, and potential exergy, the exergy equivalent to material streams for all the analyzed processes is calculated as the sum of physical $\left(e x_{m i x t, i}^{P h}\right)$ and chemical exergy ( $e x_{m i x t, i}^{C h}$ ) (Kotas, 2013; Sciubba and Wall, 2007; Querol et al., 2012).

In the evaluation of chemical exergy, the standard chemical exergy, $e x_{s t d, j}^{c h}$, term, can be obtained from reference tables (Bakshi et al., 2011; Szargut, 2005). In case the standard chemical exergy for a certain substance is not listed in the reference tables, its value is determined by considering a stoichiometric reaction through which the substance is produced from (or decomposed to) the other substances whose standard chemical exergy value is available in the reference tables (Querol et al., 2013).

There are various approaches to evaluate exergy efficiency (Kotas, 2013; Marmolejo-Correa and Gundersen, 2012; Sciubba and Wall, 2007). In this study, the evaluation of exergy efficiency $\left(\eta_{e x}\right)$ is based on the consumed-produced efficiency (Marmolejo-Correa and Gundersen, 2012), which is defined as the ratio between the change in exergy of the treated flows (the actual useful product of the system) and the sum of the external exergy required by the system to perform the desired change (Baccanelli et al., 2016):

$\eta_{e x}=\frac{\dot{E} x_{\text {out }}^{\text {mat }}-\dot{E} x_{i n}^{\text {mat }}}{\dot{E} x^{W}+\dot{E} x^{Q}}$

The numerator in Eq. (2) represents the minimum amount of mechanical work required to produce LNG from raw natural gas, i.e. the exergy associated with the separation of $\mathrm{CO}_{2}$ and the exergy associated with the liquefaction. In this way, the values of chemical exergy of the inlet and outlet streams cancel out, therefore giving a more detailed and meaningful performance indicator. The denominator represents the sum of mechanical work that must be supplied to the process in order to obtain the desired useful effect. The same approach for exergy efficiency evaluation can be found in the literature (Mokhatab et al., 2013; Venkatarathnam and Timmerhaus, 2008; Kotas, 2013; Marmolejo-Correa and Gundersen, 2012; Querol et al., 2013; Vatani et al., 2014).

\section{Process configurations}

The same feed gas composition and conditions (Table 5) have been considered for all the cases.

For a raw natural gas stream containing no $\mathrm{H}_{2} \mathrm{~S}$, a previous study (Langè et al., 2015) on AGR for the production of pipeline-quality natural gas has shown that the DPLT distillation technology will consume less energy than the classic MDEA process when the raw natural gas
Table 5

Raw natural gas (Acid $N G$ ) conditions and composition.

\begin{tabular}{ll}
\hline Properties & Values \\
\hline Molar flowrate $[\mathrm{kmol} / \mathrm{h}]$ & 35868 \\
Temperature $\left[{ }^{\circ} \mathrm{C}\right]$ & 40 \\
Pressure $[$ bar $]$ & 60 \\
Component & Mole fraction \\
$\mathrm{CH}_{4}$ & 0.8410 \\
$\mathrm{C}_{2} \mathrm{H}_{6}$ & 0.0175 \\
$\mathrm{C}_{3} \mathrm{H}_{8}$ & 0.0037 \\
$\mathrm{i}-\mathrm{C}_{4} \mathrm{H}_{10}$ & 0.0006 \\
$\mathrm{n}-\mathrm{C}_{4} \mathrm{H}_{10}$ & 0.0007 \\
$\mathrm{i}-\mathrm{C}_{5} \mathrm{H}_{12}$ & 0.0003 \\
$\mathrm{n}-\mathrm{C}_{5} \mathrm{H}_{12}$ & 0.0002 \\
$\mathrm{n}-\mathrm{C}_{6} \mathrm{H}_{14}$ & 0.0023 \\
$\mathrm{CO}_{2}$ & 0.1249 \\
$\mathrm{~N}_{2}$ & 0.0078 \\
$\mathrm{H}_{2} \mathrm{O}$ & 0.0011 \\
\hline
\end{tabular}

contains more than $10-15 \mathrm{~mol} \%$ of $\mathrm{CO}_{2}$. In this work, the value of $12.5 \mathrm{~mol} \% \mathrm{CO}_{2}$ is chosen in order to further evaluate the competitiveness of the DPLT distillation process compared to aMDEA absorption within the abovementioned range of $\mathrm{CO}_{2}$ content, through rigorous simulation of both technologies. The selected value represents a $\mathrm{CO}_{2}$ composition where the conventional aMDEA absorption technology is still considered profitable to treat the raw natural gas. So, it might highlight the possible energy saving obtained in the liquefaction process benefiting from the low-temperature level of the sweet gas stream from the DPLT $\mathrm{CO}_{2}$ removal process.

Process specifications have been determined to obtain the same outlet streams characteristics, so that the performed energy and exergy analyses are based only on differences related to mechanical works, cooling and heating duties. The content of $\mathrm{CO}_{2}$ in the final LNG product should not exceed $50 \mathrm{ppm}$, which will be the key specification for comparing the two $\mathrm{CO}_{2}$ removal technologies. The stream rich in $\mathrm{CO}_{2}$ is treated, when necessary, to be obtained liquid at 50 bar. Water vapor should be removed down to $<0.1 \mathrm{ppm}$ to avoid the formation of hydrates in the downstream liquefaction section: for LNG quality, adsorption with molecular sieves is commonly used for this purpose. Energy requirement associated to the regeneration of molecular sieves is not accounted in this work due to its relatively small value compared to the one for the AGRU and liquefaction section (Jaya, 2013).

Simulations have been performed using the Aspen HYSYS ${ }^{\circledR}$ V10 (AspenTech, 2017) process simulator. The dedicated fluid package "Acid Gas Cleaning" is utilized to simulate the amine absorption process (Dyment and Watanasiri, 2015): it allows an accurate simulation of the absorption and regeneration columns by using the rate-based model. The Advanced Model provided in the package is used: it is based on the Maxwell-Stefan theory to rigorously calculate the heat and mass-transfer rates without assuming thermal or chemical equilibrium between the vapor and liquid for each stage (Dyment and Watanasiri, 2015). For the simulation of the DPLT distillation process, the SRK EoS is used (Soave, 1972). The block flow diagrams of the different cases are represented in Fig. 2.

In the case of the aMDEA absorption process, removal of heavy hydrocarbons or natural gas liquids (NGLs recovery) is integrated with the liquefaction section (Fig. 2a) according to a common industrial practice. On the contrary, in the case of the DPLT distillation process, NGLs can be removed upstream the $\mathrm{CH}_{4}-\mathrm{CO}_{2}$ separation (Fig. 2b-1) or downstream (Fig. 2b-). Both configurations have been taken into consideration in the comparative analysis carried out in this work. Since the DPLT distillation involves operation at temperature levels below the freezing point of water, the dehydration unit is installed prior to the AGRU. 
(a)

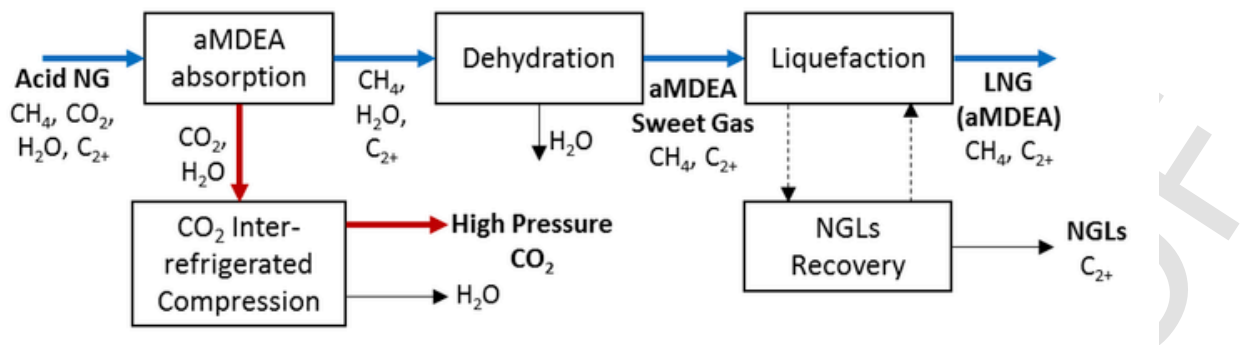

(b-1)

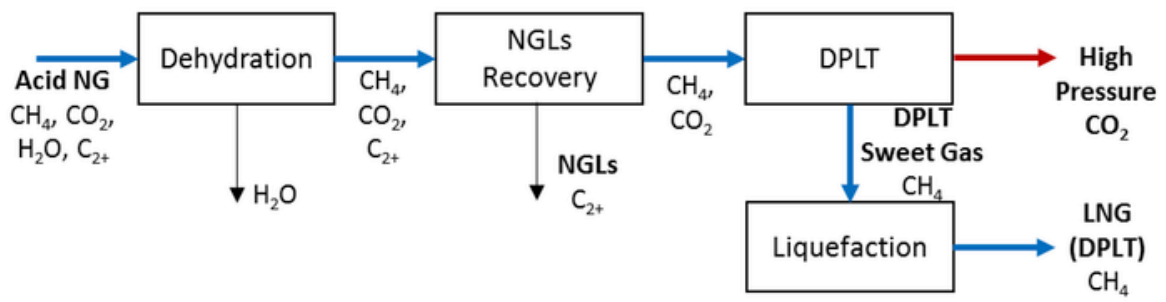

(b-2)

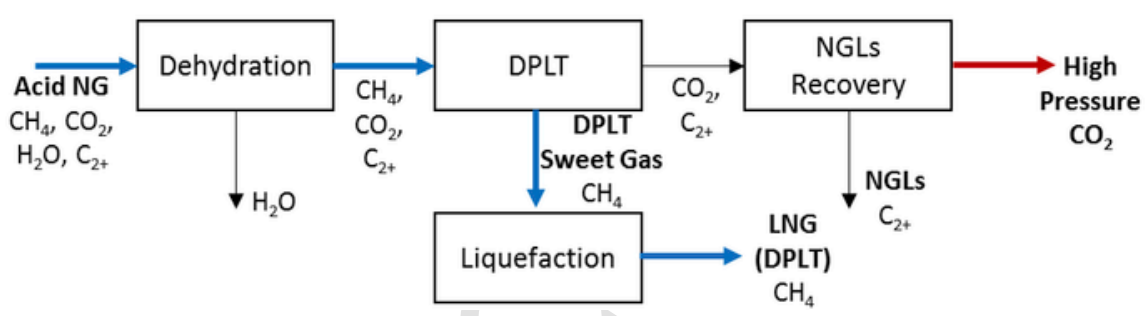

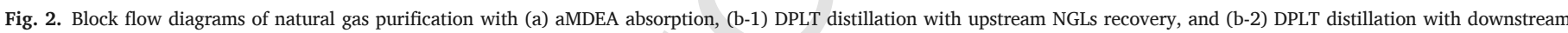
NGLs recovery for LNG production.

\subsection{Acid gas removal unit}

The aMDEA solution has $50 \mathrm{wt} \%$ amine strength (45 wt $\%$ MDEA and $5 \mathrm{wt} \% \mathrm{PZ}$ ). This value is chosen as a good compromise between the capability of the solvent to absorb acid gases, its corrosivity and viscosity. Design parameters of the absorption and regeneration columns are chosen on the basis of industrial practice and literature analysis. The absorber consists of 19 stages (trayed and packed sections) and the regenerator has 10 stages (packed column) (the number of stages refers to the number of discretization of the column required to correctly estimate the column profiles, such as temperature and composition profile).

Fig. 3 represents the process flow diagram of the aMDEA absorption and regeneration units simulated in this work. The Lean Amine solution (2) absorbs acid gas from the Acid $N G$ stream (1) in the $A b$ sorber (T-01). The Sweet Gas stream (3) obtained from the top of the absorption column (T-01) is dehydrated to produce the aMDEA Sweet Gas stream (4) suitable for further processing in the Liquefaction Unit. The Rich Amine stream (5) out from the bottom of the Absorber (T-01) is depressurized (6) and is fed to a low-pressure flash tank (V-01), where light hydrocarbons (14) are separated. The low-pressure rich amine (7) flows through the lean/rich heat exchanger (E-01) increasing its temperature to about $111.7^{\circ} \mathrm{C}$ (8). After its pressure is decreased to $2 \mathrm{bar}$ (9), it is introduced into the Regenerator (T-02). Acid gases, dissolved hydrocarbons, and some water are stripped from the rich amine and exit the regenerator as top product (10). Heat to the reboiler (E-03) of the solvent regeneration column is supplied by low-pressure saturated steam at 3.5 bar. The Regenerated Amine (12) is sent to the lean/rich heat exchanger (E-01) for heat recovery. The cooled stream (13) is further treated by a pump (P-01) and a cooler (E-02) to reach the operating pressure and temperature required for the operation of the absorption column (T-01). A make-up unit (M-01) is installed to cover the amine and water losses occurring in the process.

In order to satisfy the conditions for $\mathrm{CO}_{2}$ geo-sequestration, the pressure of the Acid Gas stream (10) is increased to 50 bar (11), the same pressure of the $\mathrm{CO}_{2}$ stream from the DPLT distillation process, by means of four stages of inter-refrigerated compression.

The reboiler duty of the Regenerator has been varied between $1.31 \times 10^{5} \mathrm{~kW}$ and $1.61 \times 10^{5} \mathrm{~kW}$. Based on the results reported in Table S1, the case with $1.51 \times 10^{5} \mathrm{~kW}$ of reboiler duty has been chosen for the following comparison with the DPLT distillation process. It is considered as the optimum value for which the specification for the sweet gas $\left(<50 \mathrm{ppm}\right.$ of $\left.\mathrm{CO}_{2}\right)$ is achieved and, at the same time, it complies with the constraints widely accepted in the gas industry for the operation of the amine absorption process.

In the DPLT distillation process, two distillation columns operating at 50 bar and 40 bar are used for the separation of acid gas and methane. Bulk removal of $\mathrm{CO}_{2}$ occurs in the high-pressure column followed by further purification of methane in the low-pressure column. The process is designed to avoid solidification of $\mathrm{CO}_{2}$ by bypassing the SLVE locus of the $\mathrm{CO}_{2}-\mathrm{CH}_{4}$ mixture. The thermodynamic validation of this process has been widely reported in several studies (Langè et al., 2015; De Guido et al., 2014). The sweet gas stream (DPLT Sweet Gas) is obtained as methane at high purity level $\left(50 \mathrm{ppm} \mathrm{CO}_{2}\right)$ and low temperature $\left(-88^{\circ} \mathrm{C}\right)$, which will be beneficial for LNG production. 


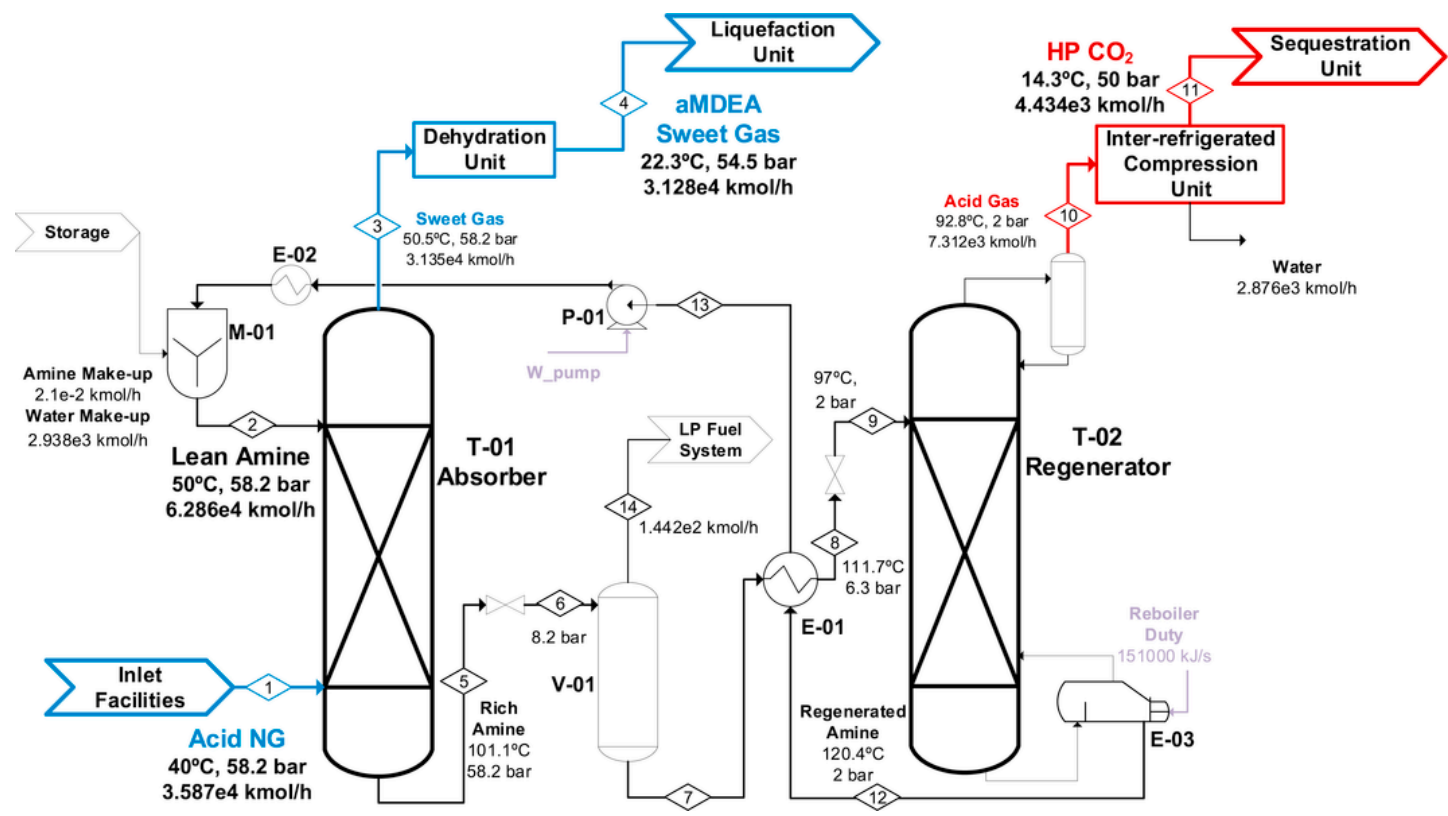

Fig. 3. Process flow diagram for the aMDEA absorption process.

The DPLT distillation process with upstream NGLs recovery is shown in Fig. 4. The Dehydrated Acid NG stream (1) is depressurized and is sent to the distillation column (T-100) operating at 35 bar for the recovery of NGLs. In this column, the Methane-rich stream (3) is separated from ethane and heavier hydrocarbons (HCs) (4). An extraction solvent (Extractive Solvent, 9), n-butane, is fed to T-100 in order to break the minimum azeotrope formed by the $\mathrm{CO}_{2}-\mathrm{C}_{2} \mathrm{H}_{6}$ mixture. The operating pressure of the column (T-100) should be lower than the critical pressure of n-butane (38 bar) (Poling et al., 2001) for allowing the separation to occur. At the same time, it is necessary to keep the pressure sufficiently high to avoid too low temperatures at the column condenser, and to avoid high energy requirements for Methane-rich stream (3) recompression (in K-01). The flowrate of the Extractive Solvent (9) is set to be as low as possible while allowing maximum recovery of $\mathrm{C}_{2}$ at the bottom (4) and maximum $\mathrm{CO}_{2}$ recovery at the top (3). The bottom product (4) is sent to the Debutanizer (T-101), operating at $35 \mathrm{bar}$, where propane and ethane are obtained as overhead product (5), while n-butane and the heavier hydrocarbons are recovered at the bottom

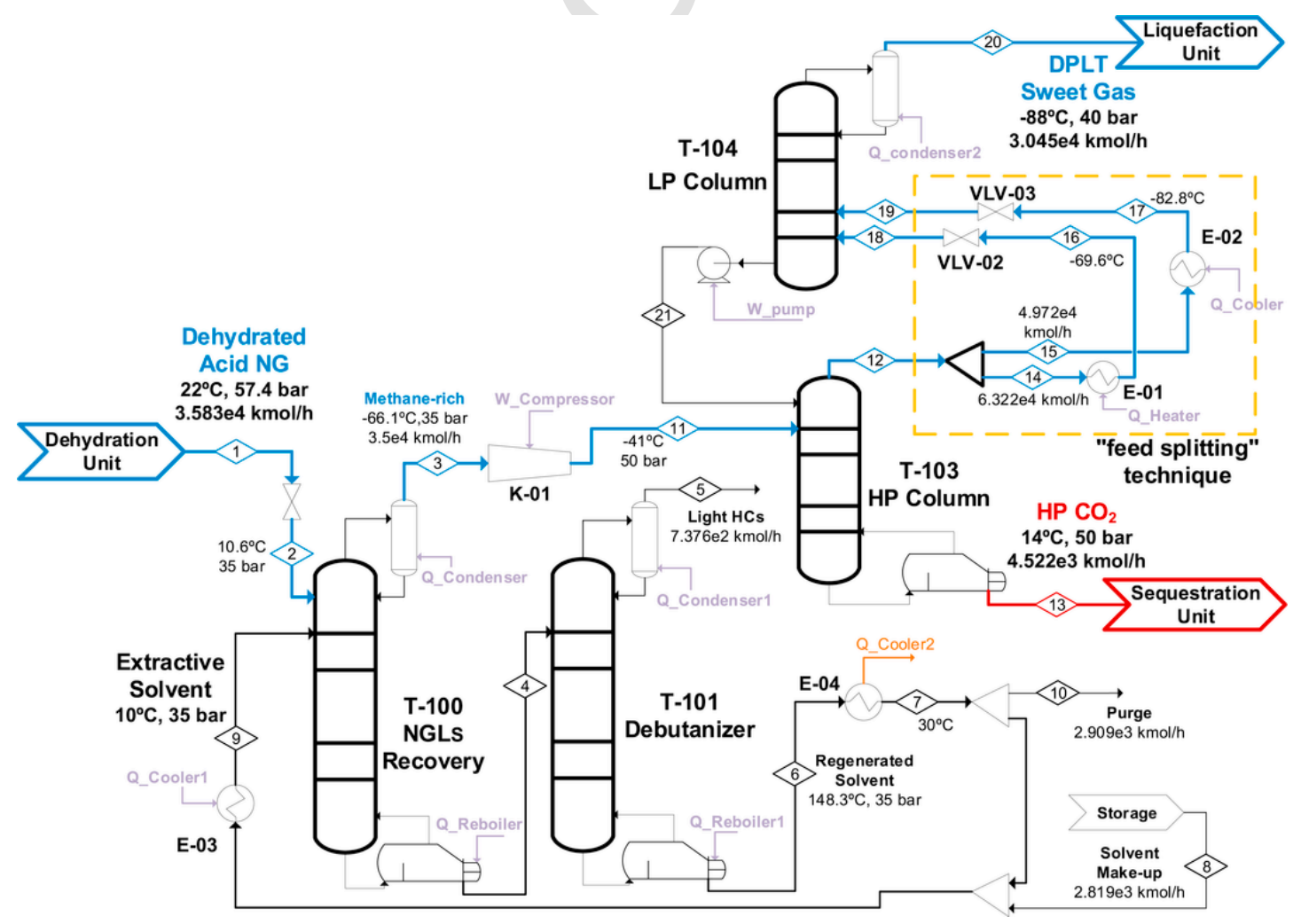

Fig. 4. Process flow diagram of the DPLT distillation process with upstream NGLs recovery. 
(6). The heat recovery (E-04) of the Regenerated Solvent stream (6) is taken into account as a saving of net equivalent methane required for the production of low-pressure steam (see section 2.1). A Solvent Make-up stream (8) is required to recover the n-butane loss through the Purge stream (10).

Methane-rich stream (3) is compressed (K-01) up to 50 bar (11) and is fed to the high-pressure (HP) distillation column (T-103). An overhead stream with high content of methane (12) and a bottom stream rich of $\mathrm{CO}_{2}$ (13) are obtained. Since the critical pressure of methane is lower than 50 bar, it is not possible to achieve the desired purity level for methane in the overhead stream. Therefore, this stream (12) is fed to the low-pressure (LP) column (T-104), operating at 40 bar, through a "feed splitting" technique (Soave et al., 2006). Solid $\mathrm{CO}_{2}$ formation is avoided by properly heating stream (14) before depressurization and the DPLT Sweet Gas stream (20) is obtained as the top product of the low-pressure column (T-104) at the desired purity level. The maximum allowable content of $\mathrm{CO}_{2}$ in the bottom product of the LP column (T-104) is maintained lower than $8 \mathrm{~mol} \%$ to avoid the formation of solid $\mathrm{CO}_{2}$. This liquid stream is pumped to the top of the high-pressure column (T-103) as a reflux stream (21).

The DPLT distillation process with downstream NGLs recovery is shown in Fig. 5. Dehydrated Acid NG stream (1) is depressurized, cooled, and fed to the HP section of the DPLT distillation process (T-103). The Methane-rich stream (4) is further purified in the low-pressure column (T-104) following the same principles explained earlier. The $\mathrm{CO}_{2}$-rich stream (5), i.e. the bottom product of T-103, is sent to the NGLs Recovery column (T-100), where $\mathrm{CO}_{2}(6)$ is separated from heavier hydrocarbons (7). The $\mathrm{CO}_{2}$-rich stream (6) is obtained at 35 bar and is compressed to 50 bar (19). The recovery of n-butane and of the other heavy hydrocarbon components follows the same process configuration used in the previous case shown in Fig. 4.

The design parameters for the distillation columns of the DPLT distillation unit combined with the NGLs recovery section are detailed in Table 6.

\subsection{Liquefaction section}

The sweet gases obtained from the aMDEA absorption process and the one from the DPLT distillation process have different conditions and compositions (Table 7). Consequently, it is necessary to make some adjustments to the liquefaction cycle typically designed for a sweet gas obtained from a conventional AGR technology. Hereafter, the major differences in the liquefaction process layouts for the two inlet sweet gas streams are outlined.

(1) The aMDEA Sweet Gas stream still contains heavy hydrocarbons (NGLs), which need to be removed in a dedicated distillation column. Since the raw gas stream contains only a small amount of NGLs, the condenser of this dedicated distillation column is integrated with the liquefaction heat exchanger. When the feed gas is rich (large amount of NGLs), it is integrated in the pre-cooling section to avoid freezing of NGLs (Fig. 6a).

(2) Due to its low temperature level $\left(-88^{\circ} \mathrm{C}\right)$, the DPLT Sweet Gas stream is directly sent to the sub-cooling main cryogenic heat exchangers (MCHEs) (Fig. 6b).

The operating conditions and the composition of the mixed refrigerant (MR) is highly dependent on the sweet gas stream. Finding optimal mass fractions of constituents of refrigerant mixtures, which have the closest match between the cooling and heating curves of sweet gas and MR, would require optimizing several variables, e.g. component mass fractions and pressure levels. In this work, the MR composition and flowrate are determined using the Knowledge Based Optimization (KBO) algorithm (Khan et al., 2013), which incorporates the knowledge of the boiling point differences in the MR components and their specific refrigeration effect in bringing a MR system close to reversible operation within the optimization algorithm that aims at minimizing the compression energy requirement.

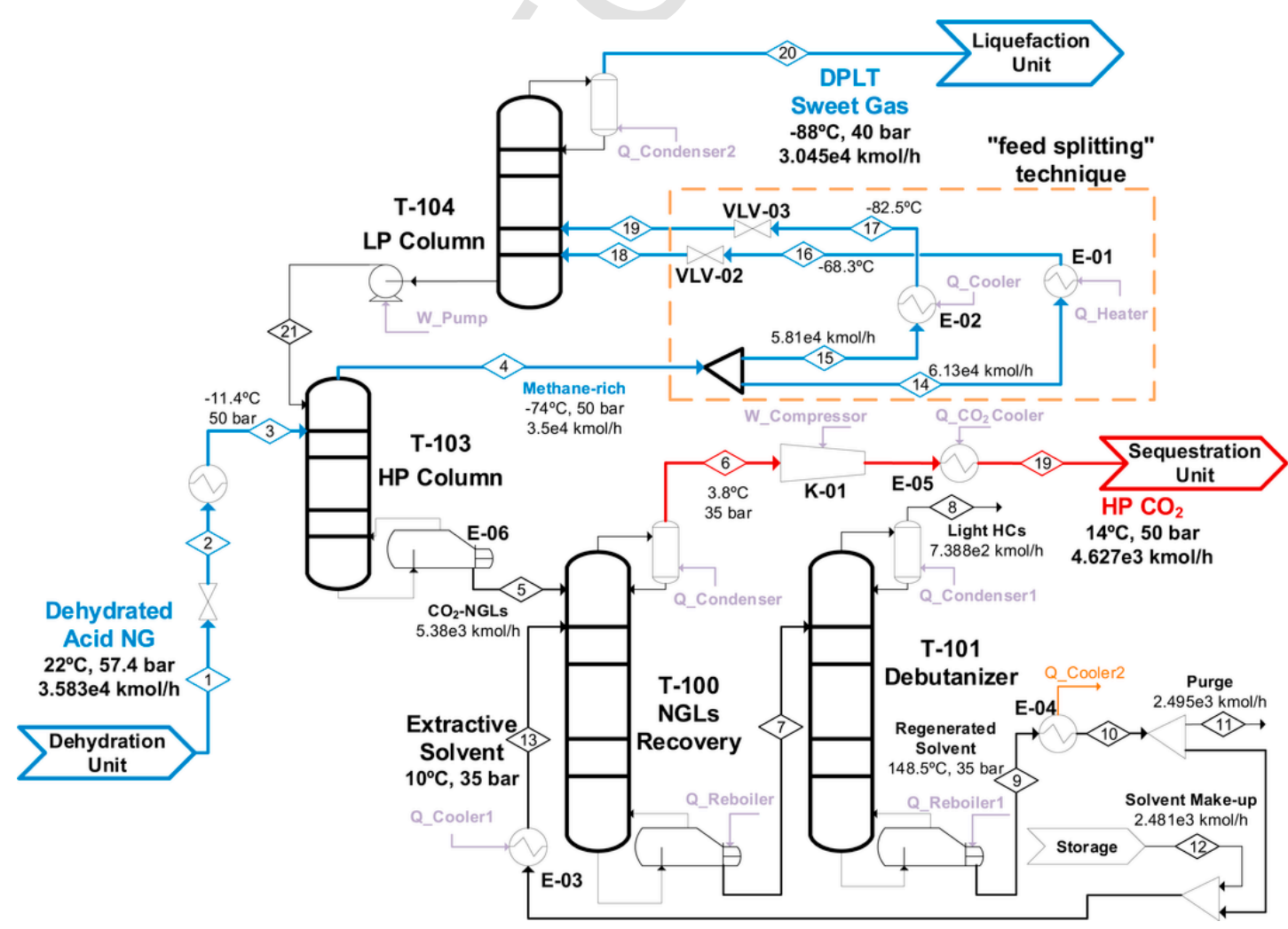

Fig. 5. Process flow diagram of the DPLT distillation process with downstream NGLs recovery. 
Table 6

Design parameters for columns in the DPLT distillation process with upstream and downstream NGLs recovery.

\begin{tabular}{ll}
\hline Columns and Parameters & Values \\
\hline $\mathrm{T}-100$ & \\
Number of Stages & 50 \\
$\mathrm{CO}_{2}$ bottom mole fraction & $5 \mathrm{E}-05$ \\
Ethane bottom recovery & 0.93 \\
$\mathrm{~T}-101$ & \\
$\mathrm{Number}$ of Stages & 50 \\
$\mathrm{nC}_{4}$ bottom recovery & 0.99 \\
$\mathrm{nC}_{4}$ bottom mole fraction & 0.94 \\
$\mathrm{~T}-103$ & \\
$\mathrm{Number}$ of Stages & 20 \\
$\mathrm{CH}_{4}$ bottom mole fraction & $9 \mathrm{E}-05$ \\
$\mathrm{~T}-104$ & 25 \\
$\mathrm{Number}$ of Stages & $5 \mathrm{E}-05$ \\
$\mathrm{CO}_{2}$ overhead mole fraction & \\
\hline
\end{tabular}

Table 7

Sweet gas from the aMDEA and the DPLT $\mathrm{CO}_{2}$ removal units.

\begin{tabular}{lll}
\hline Properties & aMDEA & DPLT \\
\hline Molar Flowrate $[\mathrm{kmol} / \mathrm{h}]$ & 31275 & 30449 \\
Temperature $\left[{ }^{\circ} \mathrm{C}\right]$ & 22.3 & -88 \\
Pressure $[$ bar $]$ & 54.45 & 40 \\
Component & Mole fraction & \\
$\mathrm{CH}_{4}$ & 0.9623 & 0.9907 \\
$\mathrm{C}_{2} \mathrm{H}_{6}$ & 0.0199 & - \\
$\mathrm{C}_{3} \mathrm{H}_{8}$ & 0.0042 & - \\
$\mathrm{i}-\mathrm{C}_{4} \mathrm{H}_{10}$ & 0.0007 & - \\
$\mathrm{n}-\mathrm{C}_{4} \mathrm{H}_{10}$ & 0.0008 & - \\
$\mathrm{i}-\mathrm{C}_{5} \mathrm{H}_{12}$ & 0.0003 & - \\
$\mathrm{n}-\mathrm{C}_{5} \mathrm{H}_{12}$ & 0.0002 & - \\
$\mathrm{n}-\mathrm{C}_{6} \mathrm{H}_{14}$ & 0.0026 & - \\
$\mathrm{CO}_{2}$ & $1.46 \mathrm{E}-05$ & $5 \mathrm{E}-05$ \\
$\mathrm{~N}_{2}$ & 0.0090 & 0.0092 \\
$\mathrm{H}_{2} \mathrm{O}$ & 0 & - \\
\hline
\end{tabular}

In the following, the three different liquefaction cycles considered in this work are briefly explained. The simulation schemes have been built based on the patents (Gaumer and Newton, 1973; Stockmann et al., 2001; Maher and Sudduth, 1975), which are described in detail in many literature works (Mokhatab et al., 2013; Venkatarathnam and Timmerhaus, 2008).

In the C3MR process (Fig. 7) the aMDEA Sweet Gas stream (1) is pre-cooled by a propane cycle to an intermediate temperature (LNG-1 to LNG-4). It is, then, liquefied and subcooled by a MR cycle in the main cryogenic heat exchangers (MCHE-1 and MCHE-2). Finally, it is depressurized to ambient pressure (1 bar) and sent to the LNG storage tank (V-LNG), where a fraction (8\%) of vapor is released as Boil-Off-Gas (BOG).

The MR stream (11) is partially condensed by the propane pre-cooling cycle. The Heavy Key (17) and Light Key (13) streams are further cooled down in MCHE-1. The cooled heavy key stream (18) is flashed in the Joule-Thomson valve (JT1) reducing its temperature and, then, it is sent back to MCHE-1 to provide the duty required for liquefaction. The cooled light key stream (14) is further subcooled in MCHE-2, flashed across the Joule-Thomson valve (JT2), and is utilized to provide sub-cooling duty in MCHE-2. The low-pressure and heated MR stream (20) is sent to the MR multistage compression section (K-01 to K-04) to bring its pressure and temperature to the initial conditions and, hence, to complete the MR loop.

The Propane stream (21) evaporating pressure and flowrate have been determined on the basis of the required refrigeration duty of the feed sweet gas (1) and of the MR (11). Propane and MR properties for liquefaction of the aMDEA Sweet Gas and of the DPLT Sweet Gas are available in Table S2. A lower rate of propane (almost 50\%) is needed for liquefaction of the DPLT Sweet Gas since in this case the propane cycle is only used to pre-cool the MR. A lower rate of the MR is also required due to the lower temperature level of the DPLT Sweet Gas stream.

The Mixed Fluid Cascade (MFC) liquefaction technology has three different MR cycles, i.e. pre-cooling, condensing, and sub-cooling. Each of these cycles uses different mixed refrigerant compositions and operating conditions (Table S3 and Table S4). The process flow diagram of the MFC for liquefaction of the aMDEA Sweet Gas is illustrated in Fig. 8. Two heat exchangers (LNG-1 and LNG-2) are used for pre-cooling, and the other two ones (MCHE-1 and MCHE-2) are for condensing (liquefaction) and sub-cooling, respectively.

The Pre-cooling MR (11) cycle is responsible for cooling the sweet gas stream (1), the Condensing MR (17), and the Sub-cooling MR (21) in LNG-1. A part of the pre-cooling refrigerant (15) is depressurized to an intermediate pressure and is used as the cold side fluid in the first heat exchanger (LNG-1). The rest (13) is further cooled and depressurized, and it provides the cooling duty in LNG-2. The pre-cooled Condensing MR (18) is further cooled down in MCHE-1. It is, then, depressurized (19), and it is utilized to cool the condensing (18) and sub-cooling (22) refrigerant, as well as to liquefy the sweet gas streams $(5,7)$. The pre-cooled Sub-cooling MR stream (22) is further cooled down in MCHE- 1 and in MCHE-2 and then depressurized, providing the final sub-cooling of the sweet gas (8). In each cycle, the corresponding MR stream is completely vaporized and is restored to its initial pressure and temperature through intercooled compression stages (K-01 to K-02 for Pre-cooling MR; K-03 to K-06 for Condensing MR; K-07 to K-10 for Sub-cooling MR).

The operation of the MFC process is flexible since each refrigerant cycle can be monitored separately. However, it takes longer to start-up and line up because of the need for precise blending of the refrigerant mix for each MR cycle (Venkatarathnam and Timmerhaus, 2008). In an operation with high occurrence of start-up and shutdown, frequent adjustment to the refrigerant composition is required.

The Single Mixed Refrigerant (SMR) process (Fig. 9) uses a lower number of compressors (K-01 to K-04) and heat exchangers (MCHE-1 and MCHE-2), compared to the other liquefaction processes: therefore, it is suitable for operations where space is limited. The composition and operating pressure of the $M R$ stream (8) (Table S5) are chosen so that it is partially condensed in the last condenser (E-01) of the MR intercooled compression train. The vapor (9) and liquid (12) phases are separated. The liquid stream (12), mainly containing the heavy components, is fed to MCHE-1, cooled down, depressurized in the JT1 valve (14), and is utilized to pre-cool the streams entering MCHE- $1(1,4,9$, and 12). The vapor stream (9), mainly containing the light components, is pre-cooled in MCHE-1 and is sub-cooled in MCHE-2. It is depressurized in the JT2 valve at low-temperature (11) and is sent back to MCHE-2 for the liquefaction and final sub-cooling of the sweet gas stream (5). The heated and vaporized MR stream (15) is sent to the inter-refrigerated multistage compression section (K-01 to K-04) to close the MR cycle.

\section{Results and discussion}

As shown in Fig. 10, the aMDEA absorption process and the DPLT distillation process with downstream NGLs recovery require the same consumption of specific equivalent methane. Even with only $12.5 \mathrm{~mol} \%$ of $\mathrm{CO}_{2}$ in the inlet natural gas (Acid $N G$ ), the DPLT distillation process proves its applicability to economically purify the contaminated natural gas. The high energy consumption in the aMDEA absorption process is primarily due to the reboiler duty required in the solvent regeneration column. 
(a)

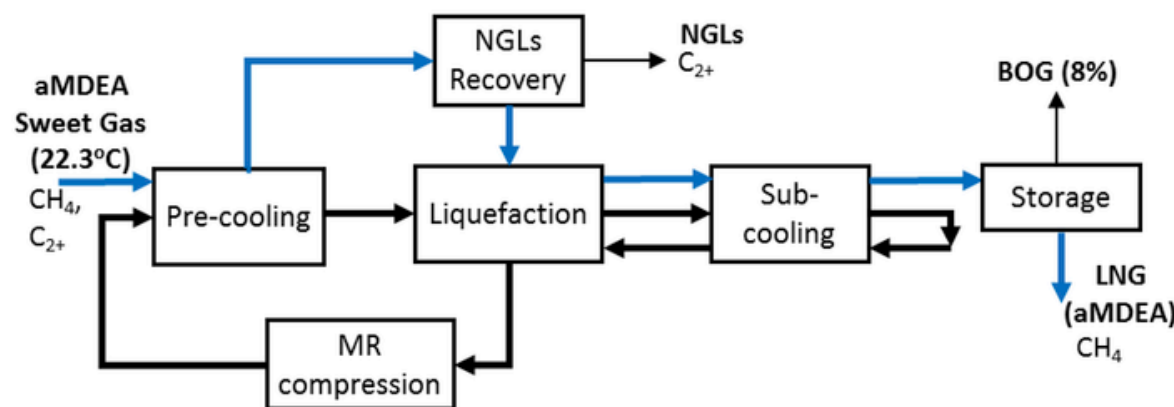

(b)

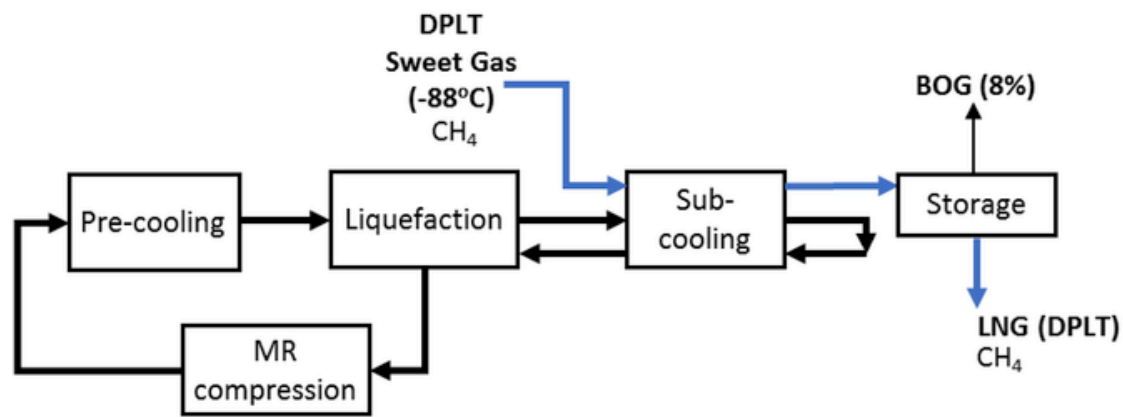

Fig. 6. Block flow diagrams for liquefaction of (a) aMDEA Sweet Gas and (b) DPLT Sweet Gas.

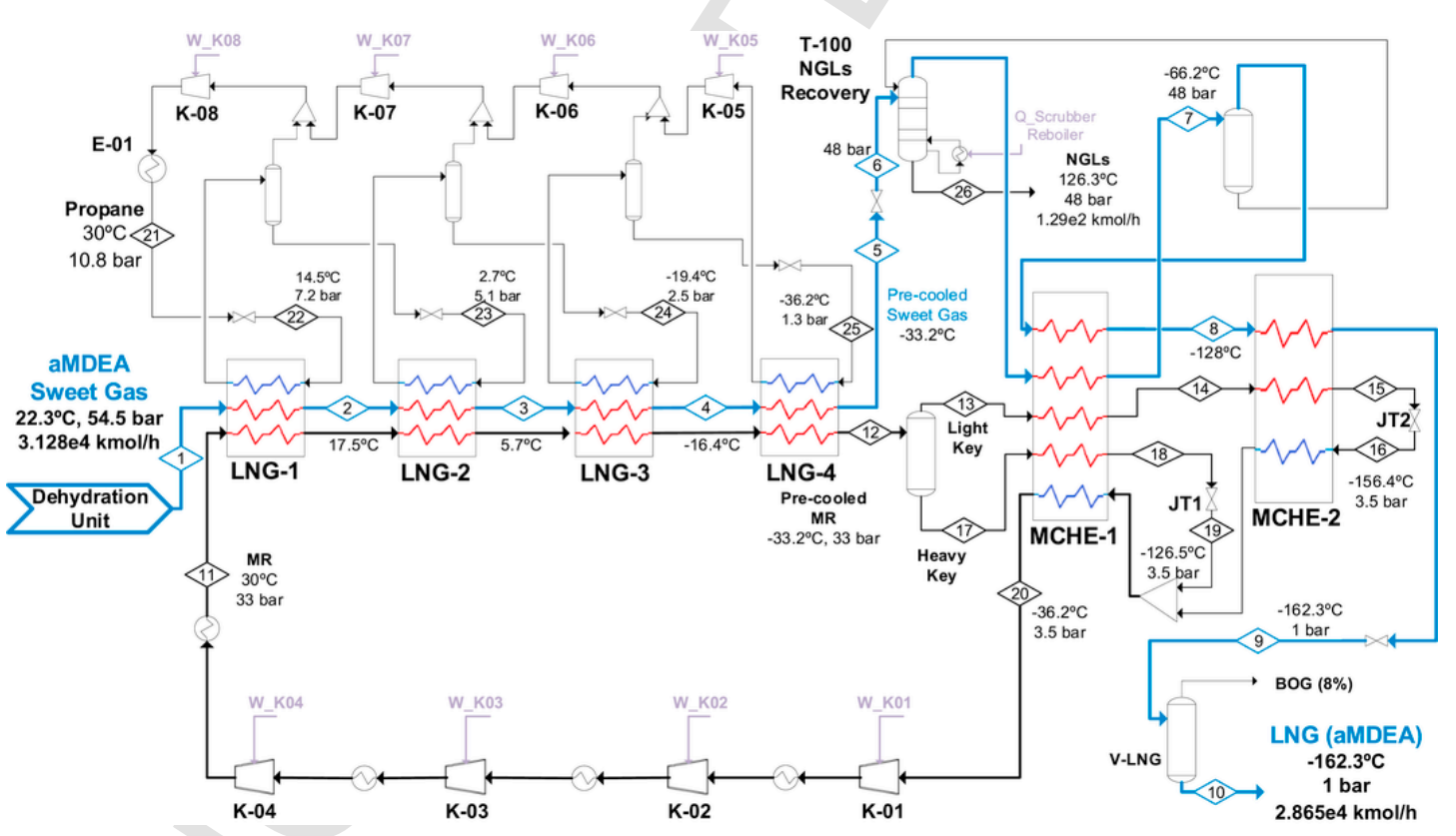

Fig. 7. Process flow diagram of the C3MR liquefaction cycle for the aMDEA Sweet Gas.

The specific equivalent methane consumption of the DPLT distillation process with upstream NGLs recovery is higher compared to the one of the DPLT downstream case. The condenser of column T-100 in the upstream case (Fig. 4), which operates at $-66^{\circ} \mathrm{C}$, consumes a high amount of refrigeration duty. On the contrary, in the other case (i.e., the one involving the separation of NGLs downstream of the DPLT distillation process, as shown in Fig. 5), this condenser is operated at $c a$. $4{ }^{\circ} \mathrm{C}$. Thus, a lower amount of energy is required for refrigeration. In addition to that, in the upstream case, the inlet Acid NG stream (1) is initially expanded to 35 bar in order to allow the separation of NGLs from methane and $\mathrm{CO}_{2}$ in the distillation column (T-100 in Fig. 4). Then, the Methane-rich stream (3) is compressed back to 50 bar (in K-01 of Fig. 4) for the bulk $\mathrm{CO}_{2}$ separation in the high-pressure column (T-103) of the DPLT distillation process, with an additional energy requirement for compression.

In terms of exergy efficiency, the DPLT distillation process (both with upstream and downstream NGLs recovery) is much better compared with the aMDEA absorption process (Fig. 11).

Figs. 12-14 present the system boundary for each scheme with its associated energy and material interactions. From these figures, it can 


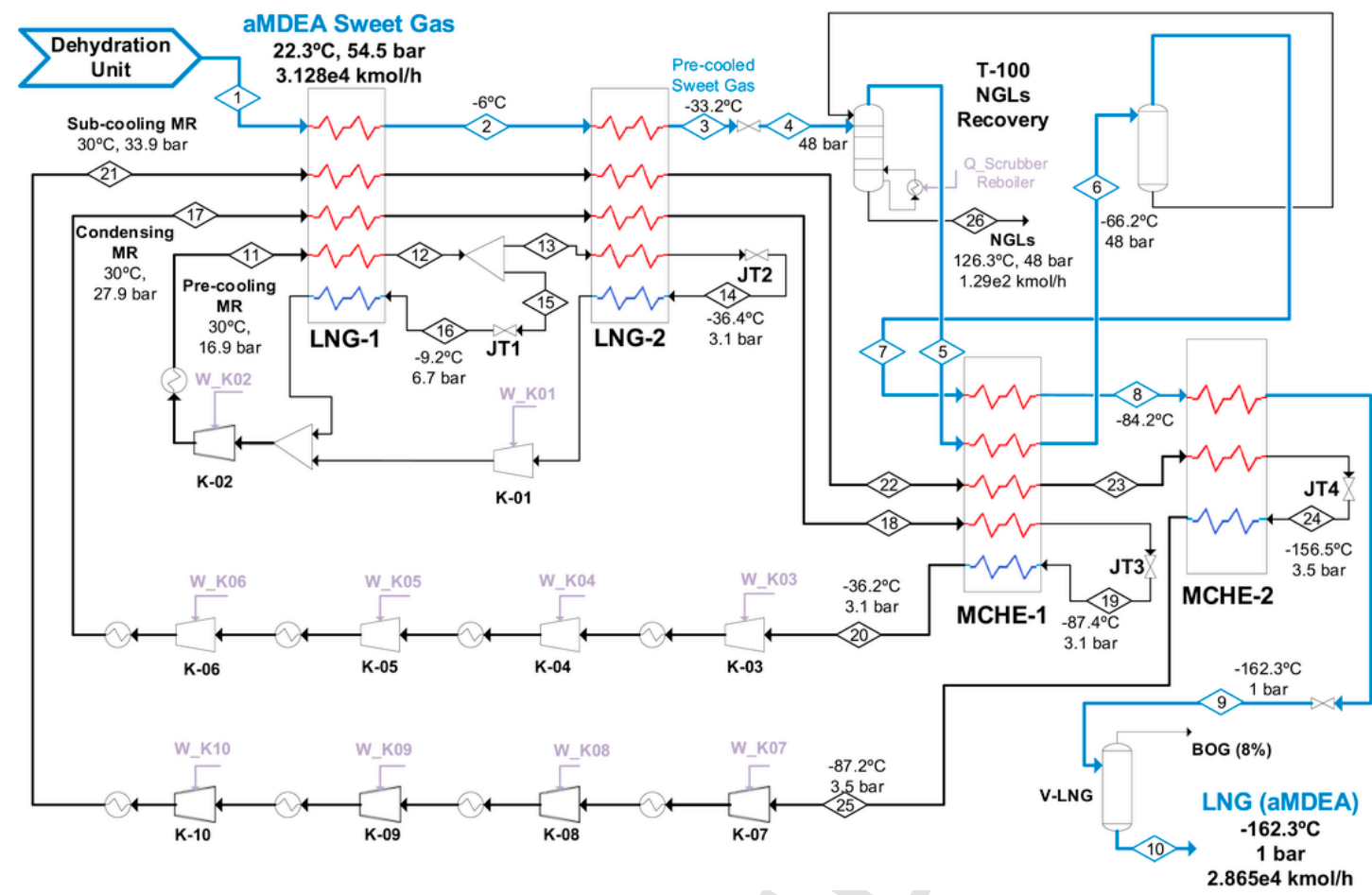

Fig. 8. Process flow diagram of the MFC liquefaction cycle for the aMDEA Sweet Gas.

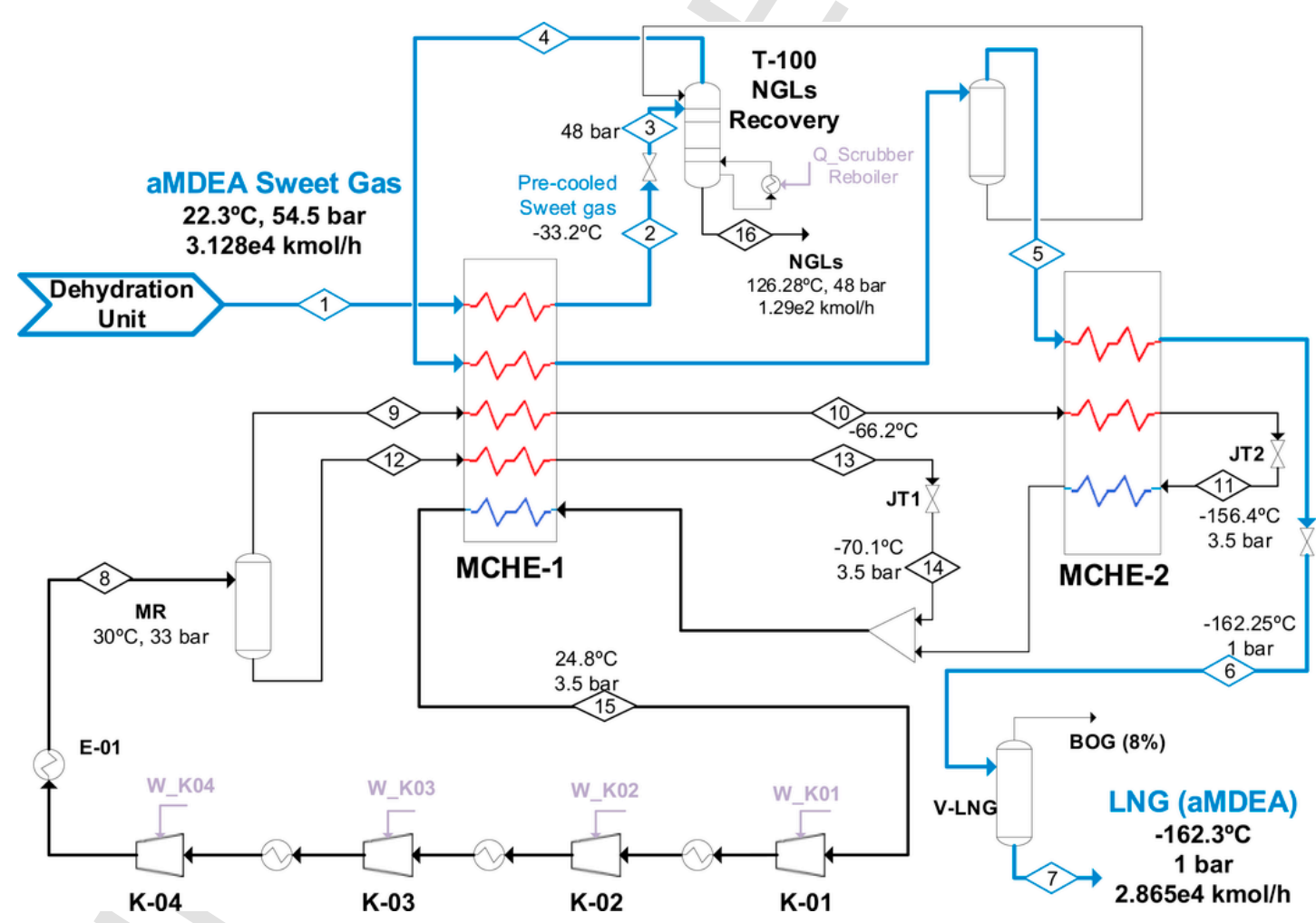

Fig. 9. Process flow diagram of the SMR liquefaction cycle for the aMDEA Sweet Gas.

be observed that the exergy difference between the outlet and inlet material streams (grey color) is much higher in the DPLT distillation cases. The reason for this is the temperature level of the DPLT Sweet Gas stream going out from the system, which is much lower compared to that of the inlet Acid NG stream. Hence, the exergy supplied (blue arrows) to the DPLT schemes is more useful for the process, i.e. to obtain the desirable changes (see the definition of exergy efficiency).
Moving to the liquefaction unit, the specific equivalent methane consumption for the liquefaction of the DPLT Sweet Gas is much lower (by up to $30 \%$ ) compared to that required for the liquefaction of the $a M D E A$ Sweet Gas (Fig. 15). This proves the benefits of producing a sweet gas at low temperature, i.e. of the synergy between the $\mathrm{CO}_{2}$ removal based on the DPLT distillation process and the liquefaction process for LNG production. 


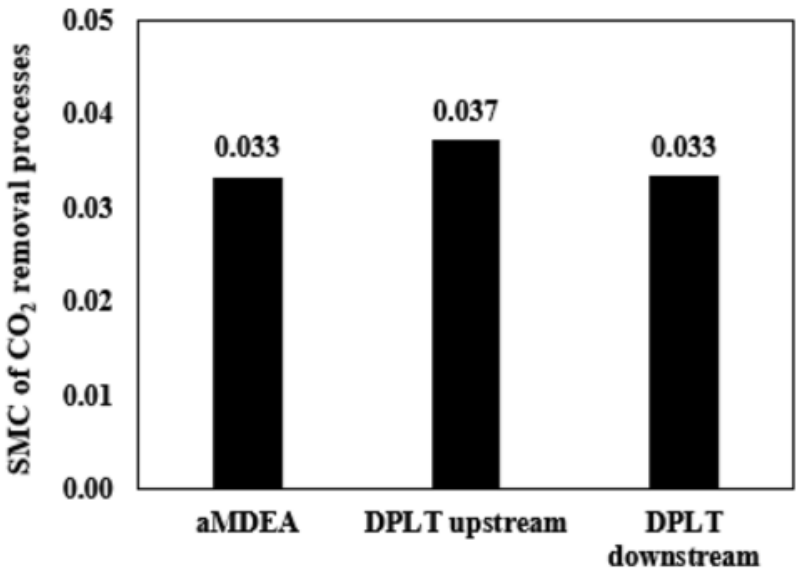

Fig. 10. Specific equivalent methane consumption (SMC) $\left[\frac{\mathrm{kg}_{\mathrm{CH}_{4}, \mathrm{eq}}}{\mathrm{kg}_{\mathrm{CH}_{4}, \mathrm{in}}}\right]$ of different $\mathrm{CO}_{2}$ removal schemes.

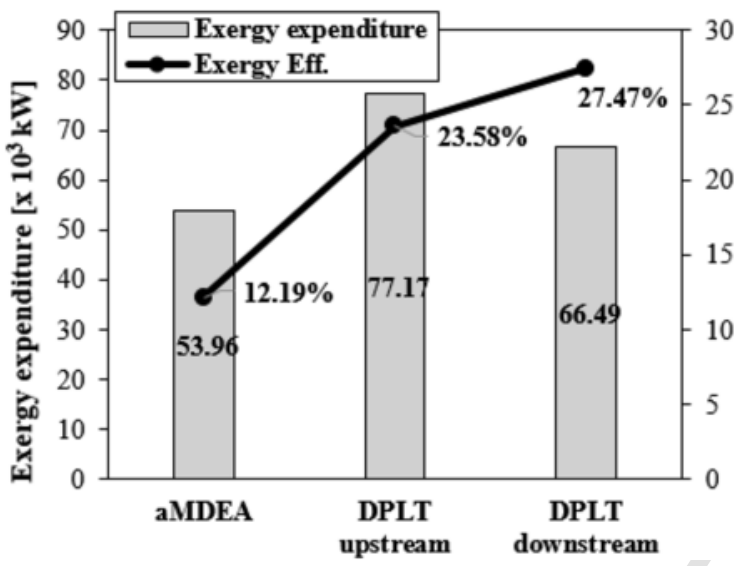

Fig. 11. Exergy $\left[\mathrm{x} 10^{3} \mathrm{~kW}\right]$ and exergy efficiency [\%] of different $\mathrm{CO}_{2}$ removal schemes

For the liquefaction of the aMDEA Sweet Gas, the specific equivalent methane consumption with the MFC and the C3MR processes is similar. On the other hand, for liquefaction of the DPLT Sweet Gas, the MFC process is characterized by a lower amount of specific equivalent methane consumption. The benefits of using the MFC technology are summarized in the following.
- Optimum heat exchange between natural gas and the corresponding MR due to the flexibility of using different refrigerant mixtures at different cooling temperature levels.

- The total flowrate of the MR is smaller and, thus, requires a lower compression duty.

- Each refrigeration cycle (i.e., pre-cooling, condensing, and sub-cooling) operates at different pressure levels, hence not all the refrigerant is expanded to the lowest pressure and compressed back to the highest pressure.

Fig. 16 presents the exergy expenditure and exergy efficiency of the different liquefaction cycles considered in this work. The exergy expenditure to liquefy the DPLT Sweet Gas is much lower compared to the one required for the aMDEA Sweet Gas. Since the DPLT Sweet Gas is already at low temperature, there is no additional duty needed for pre-cooling the sweet gas stream. Hence, a lower flowrate of pre-cooling refrigerant is required and, thus, a lower compression power. For this reason, less exergy input for the propane cycle in the liquefaction of the DPLT Sweet Gas is required.

The exergy efficiency for liquefaction of the DPLT Sweet Gas is lower compared to the one for liquefaction of the aMDEA Sweet Gas. This is the consequence of the definition of exergy efficiency, i.e. the desired change in the system divided by the provided exergy (work and heat) to obtain such change. The temperature change occurring in the liquefaction of the DPLT Sweet Gas (from $-88^{\circ} \mathrm{C}$ to $-162^{\circ} \mathrm{C}$ ) is much smaller compared to the change occurring in the aMDEA Sweet Gas liquefaction cycles (from $22^{\circ} \mathrm{C}$ to $-162^{\circ} \mathrm{C}$ ). Nevertheless, the exergy efficiency for the liquefaction of the DPLT Sweet Gas is improved by using the MFC scheme. This is due to the same reasons explained earlier.

The performances of the overall LNG production chain for the different process schemes analyzed in this work is discussed in the following. It is the combination of the schemes selected from the previous sections based on the lowest specific equivalent methane consumption and highest exergy efficiency: the MFC is the most suitable scheme for liquefaction of the DPLT Sweet Gas and the C3MR is the best for liquefaction of the aMDEA Sweet Gas.

For the overall exergy efficiency evaluation, end-to-end block diagrams have been developed to illustrate the system boundary for each case. The illustrations are reported only for the aMDEA $\mathrm{CO}_{2}$ removal process combined with the C3MR liquefaction cycle (Fig. 17) and for the DPLT distillation process with downstream NGLs recovery combined with the MFC liquefaction cycle (Fig. 18). All the cases have Acid NG as the primary inlet material stream and high-pressure $\mathrm{CO}_{2}$, recovered heavy hydrocarbons, and final LNG as the outlet material streams. The produced LNG stream used in the exergy analysis is the one before

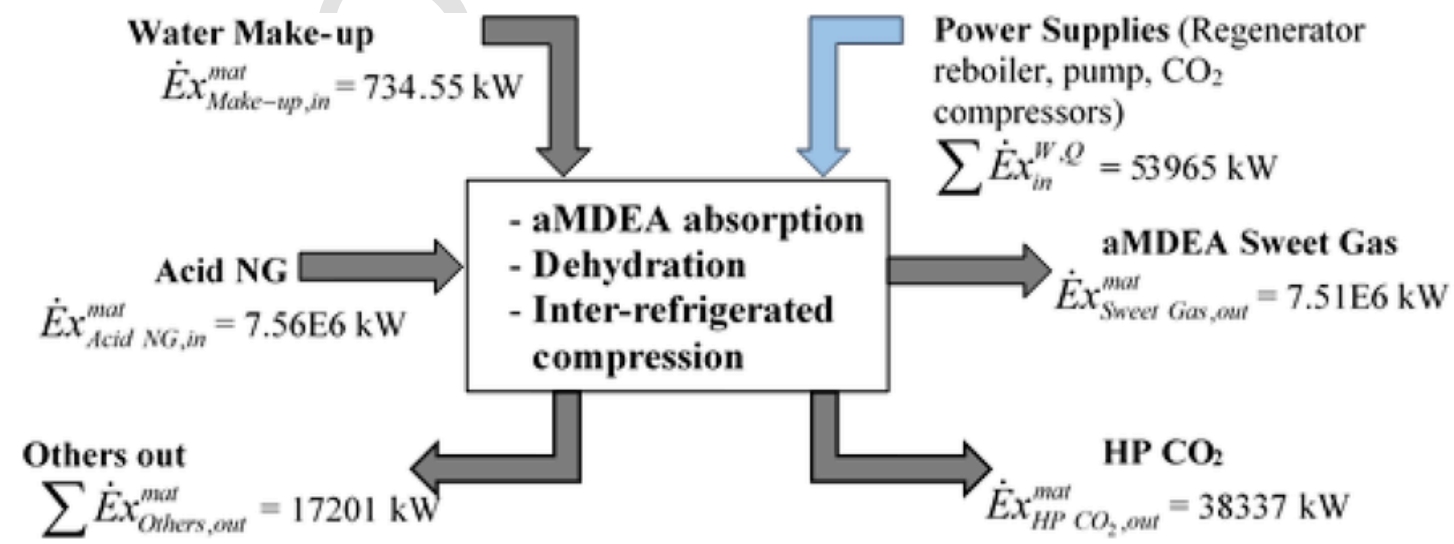

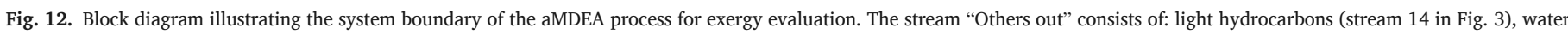
from Dehydration Unit, water from Inter-refrigerated Compression Unit. 


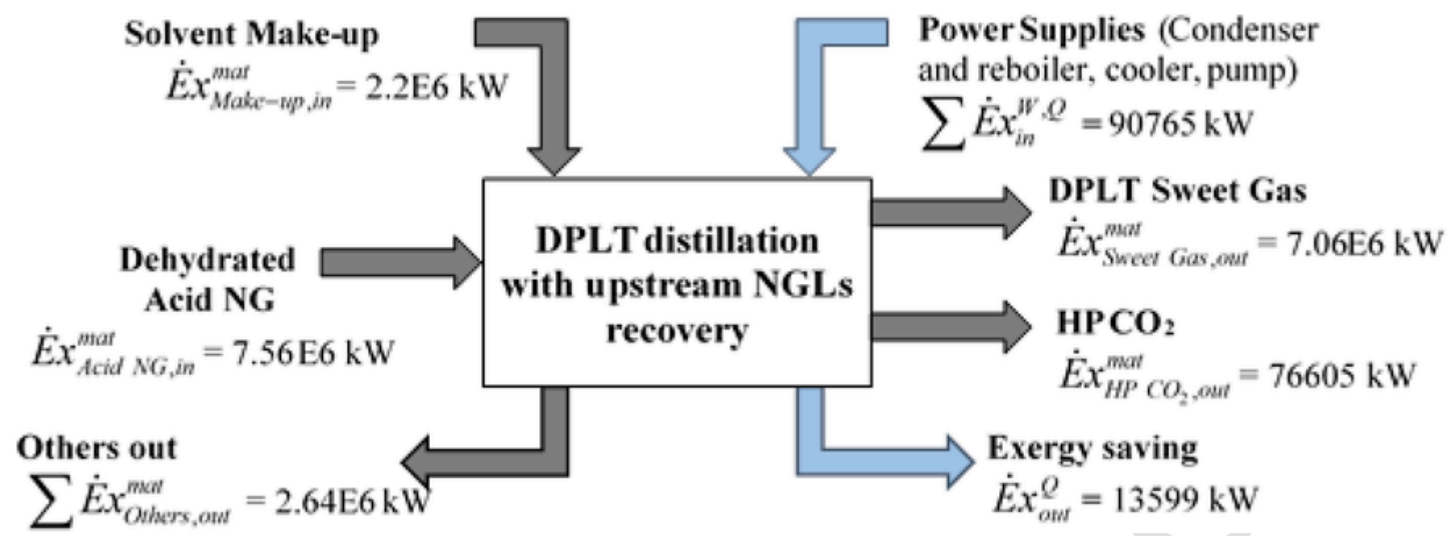

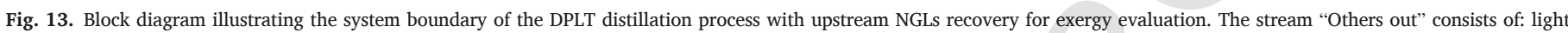

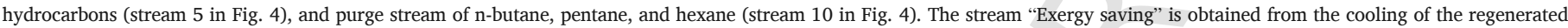
solvent at high temperature (cooler E-04 in Fig. 4).

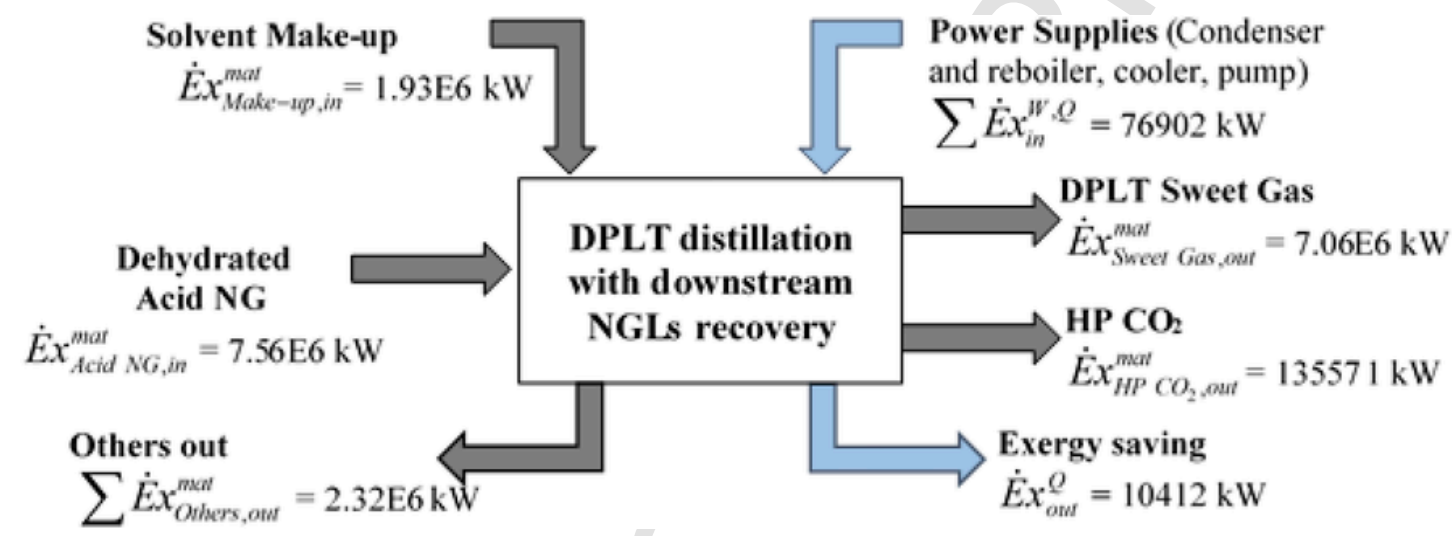

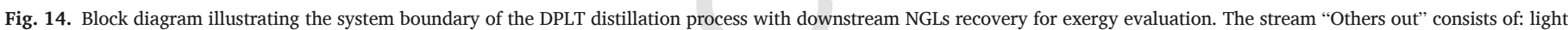

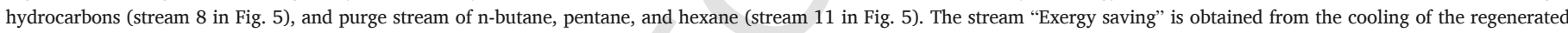
solvent at high temperature (cooler E-04 in Fig. 5).

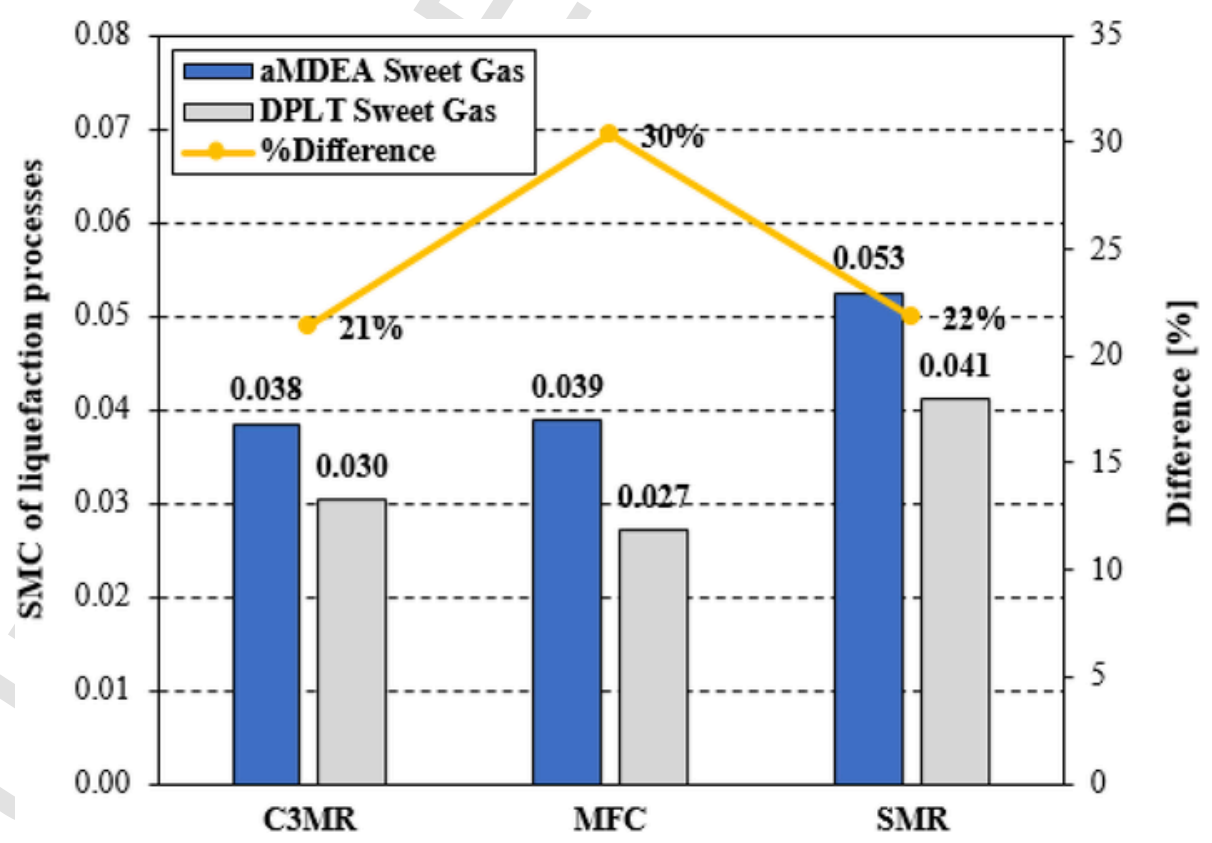

Fig. 15. Specific equivalent methane consumption (SMC) $\left[\frac{\mathrm{kg}_{\mathrm{CH}_{4}, \mathrm{eq}}}{\mathrm{kg}_{\mathrm{CH}_{4}, \mathrm{in}}}\right]$ of liquefaction processes for the aMDEA Sweet Gas (blue bars) and for the DPLT Sweet Gas (grey bars). 

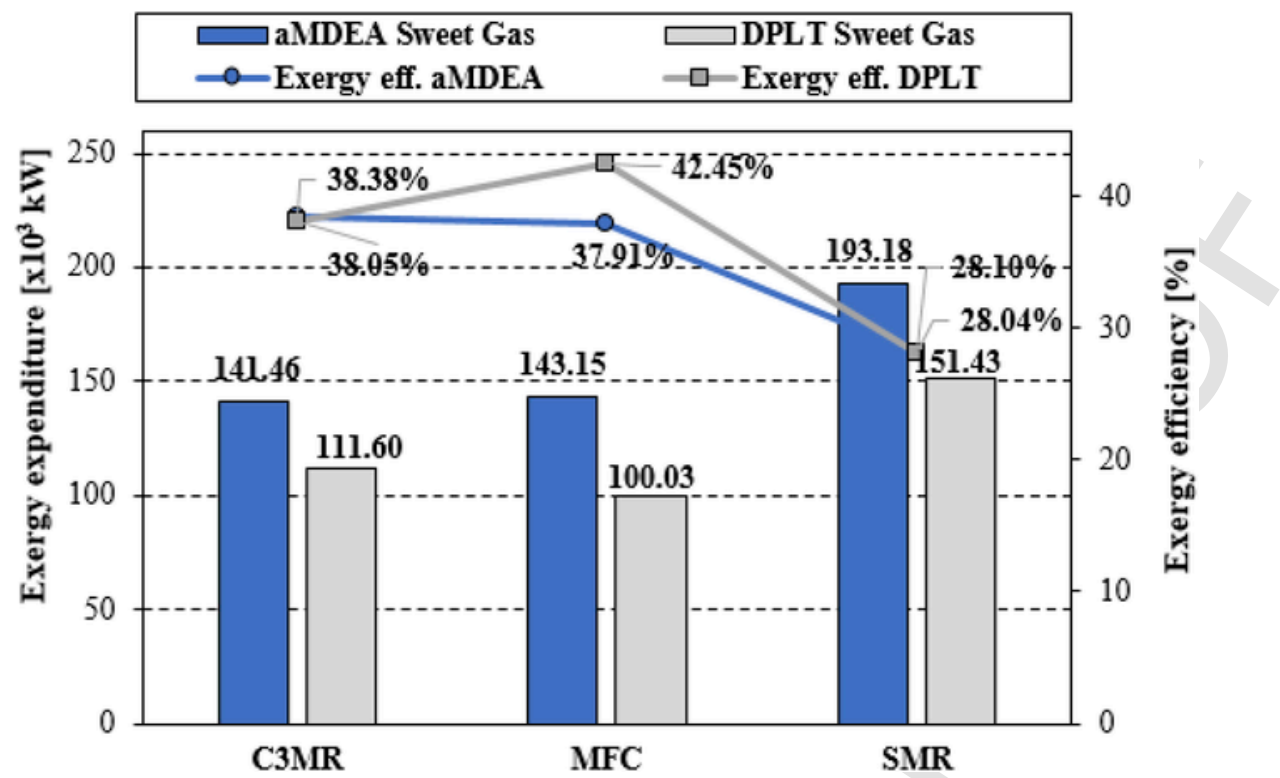

Fig. 16. Exergy expenditure [x $\left.10^{3} \mathrm{~kW}\right]$ and exergy efficiency [\%] of various liquefaction cycles for the aMDEA Sweet Gas (blue color) and the DPLT Sweet Gas (grey color).

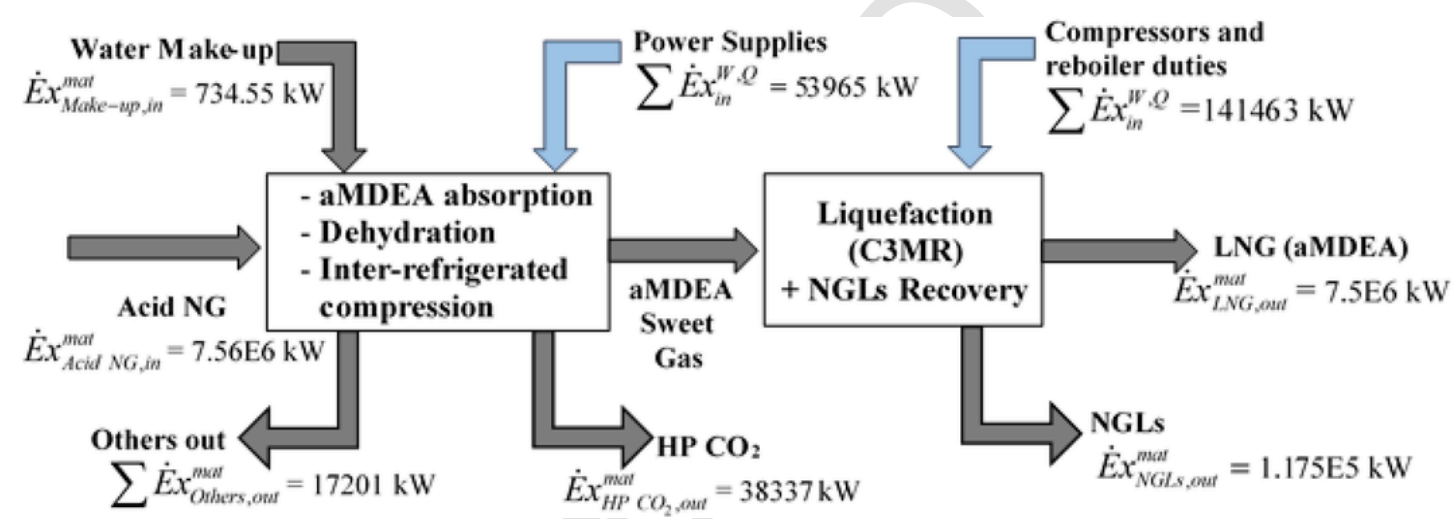

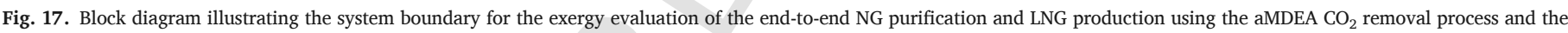
C3MR liquefaction cycle.

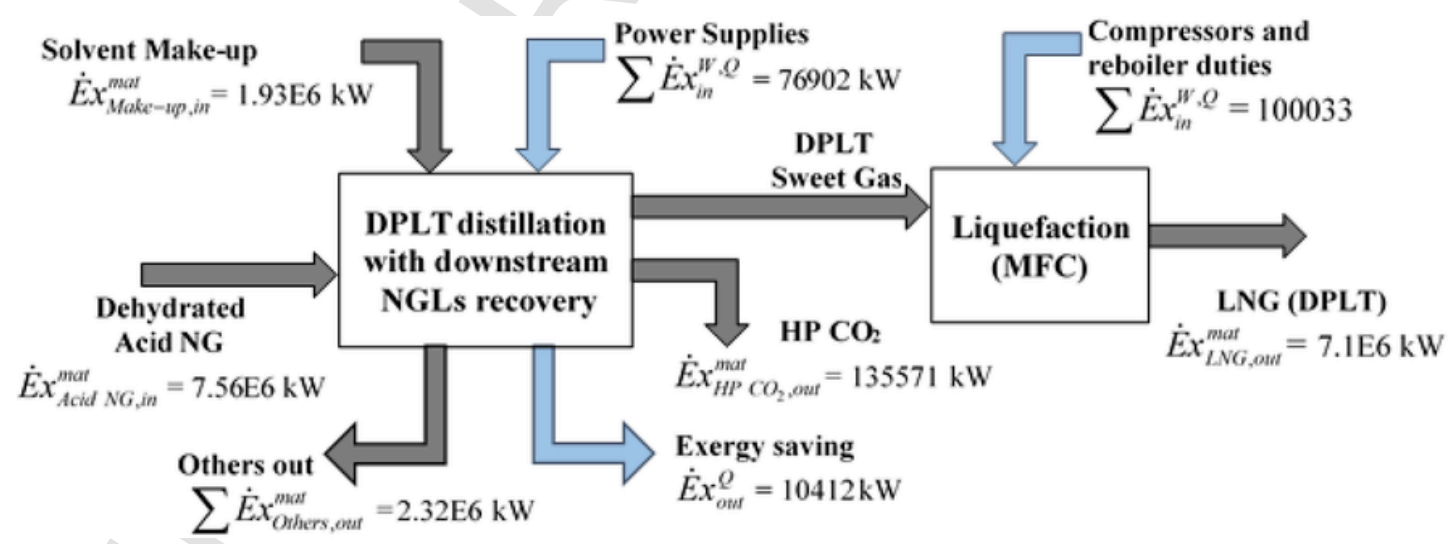

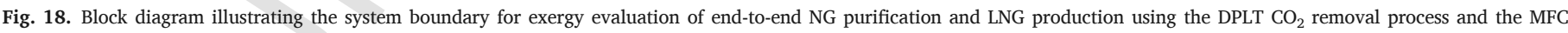
liquefaction cycle.

the storage tank where the loss due to BOG occurs (e.g., stream (9) before V-LNG in Fig. 7). Other material and energy streams for each technology are reported in the corresponding figures.

Since the total specific equivalent methane consumption (SMC) for the two selected overall LNG production chains can be easily determined by combining the results reported in Fig. 10 and in Figs. 11 and
19 reports the ratio between the total equivalent methane consumed by each selected overall scheme and the total amount of produced LNG. Even though the DPLT distillation process with upstream NGLs recovery consumes more energy than the aMDEA for $\mathrm{CO}_{2}$ removal (as also shown in Fig. 10), when combined with the liquefaction process, the total consumption is less. Since the sweet gas is obtained at low tem- 


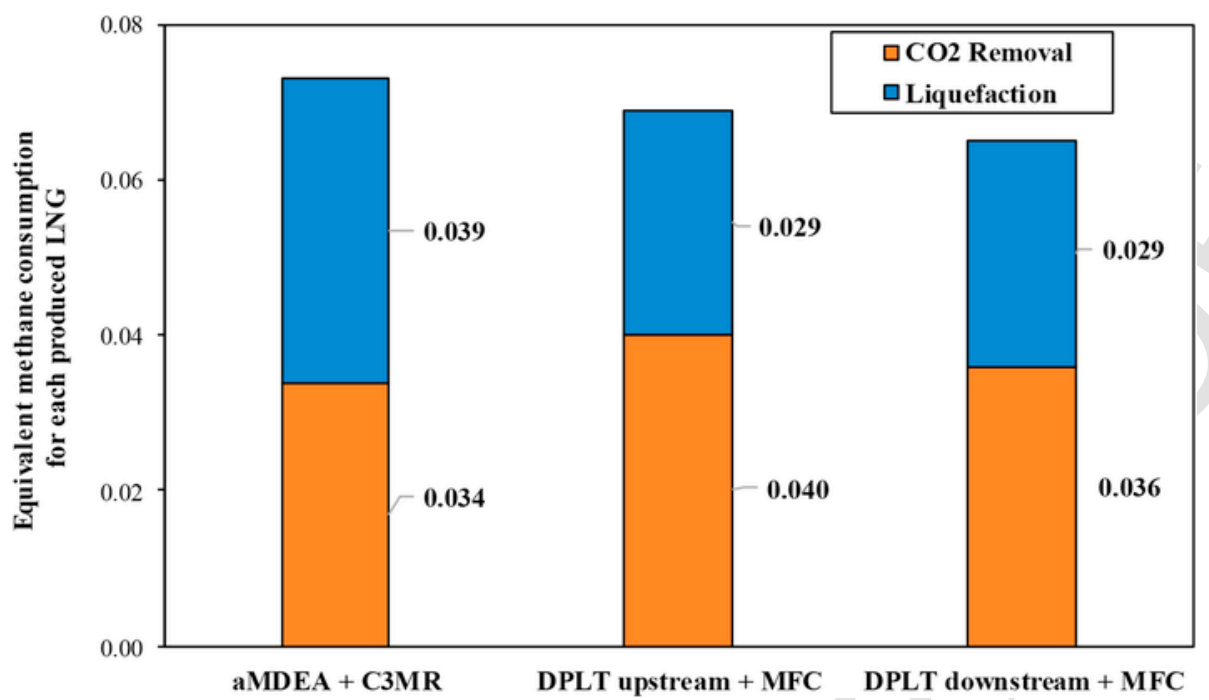

Fig. 19. Equivalent methane consumption for each produced LNG $\left[\frac{\mathrm{kg}_{\mathrm{CH}_{4}, \mathrm{eq}}}{\mathrm{kg}_{\mathrm{LNG}}}\right]$ of the different selected overall LNG production chain schemes, as specified in the figure.

perature, it requires less amount of equivalent methane for liquefaction. The overall exergy efficiency (Fig. 20) for the cases in which the DPLT distillation technology is used for $\mathrm{CO}_{2}$ removal is higher compared to the conventional aMDEA process. This confirms the benefit of using the DPLT distillation process for the purification of contaminated natural gas when LNG is the final desired product.

From the results of the energy analysis and of the exergy efficiency evaluation, it can be concluded that the best LNG production scheme is the one based on the DPLT $\mathrm{CO}_{2}$ removal with downstream NGLs recovery combined with the MFC liquefaction cycle. The overall consumption of equivalent methane is the lowest, being $16 \%$ lower than that required by the conventional aMDEA with the C3MR liquefaction process, and it has the highest exergy efficiency.

\section{Conclusions}

This work deals with the production of LNG, considering two processes for $\mathrm{CO}_{2}$ removal from natural gas (chemical absorption with the activated-MDEA solvent and the new Dual Pressure Low-Temperature distillation technology), combined with several liquefaction processes, including Propane-Mixed Refrigerant (C3MR), Mixed Fluid Cascade (MFC) and Single Mixed Refrigerant (SMR. The thermody- namic performances of the resulting processes have been evaluated and compared by means of energy (net equivalent methane) and exergy analyses.

This paper demonstrates that the DPLT distillation technology provides the vehicle to economically exploit high $\mathrm{CO}_{2}$-content natural gas reserves in order to produce LNG. Although the amount of $\mathrm{CO}_{2}$ in the inlet natural gas is only $12.5 \mathrm{~mol} \%$, the DPLT distillation process has shown its competitiveness in removing $\mathrm{CO}_{2}$ when compared to the aMDEA absorption one. This advantage is emphasized when the liquefaction process is also taken into account. Although the aMDEA absorption and DPLT distillation processes consume a comparable amount of equivalent methane for $\mathrm{CO}_{2}$ removal, when combined with the liquefaction cycle, the DPLT distillation process consumes a lower amount of equivalent methane to produce LNG. Therefore, this proves the synergy between the low-temperature $\mathrm{CO}_{2}$ removal technology and the liquefaction process due to the low-temperature level of the sweet gas stream.

\section{Acknowledgments}

The authors would like to thank Professor Kazuho Nakamura of Yokohama National University for the opportunity of conducting some

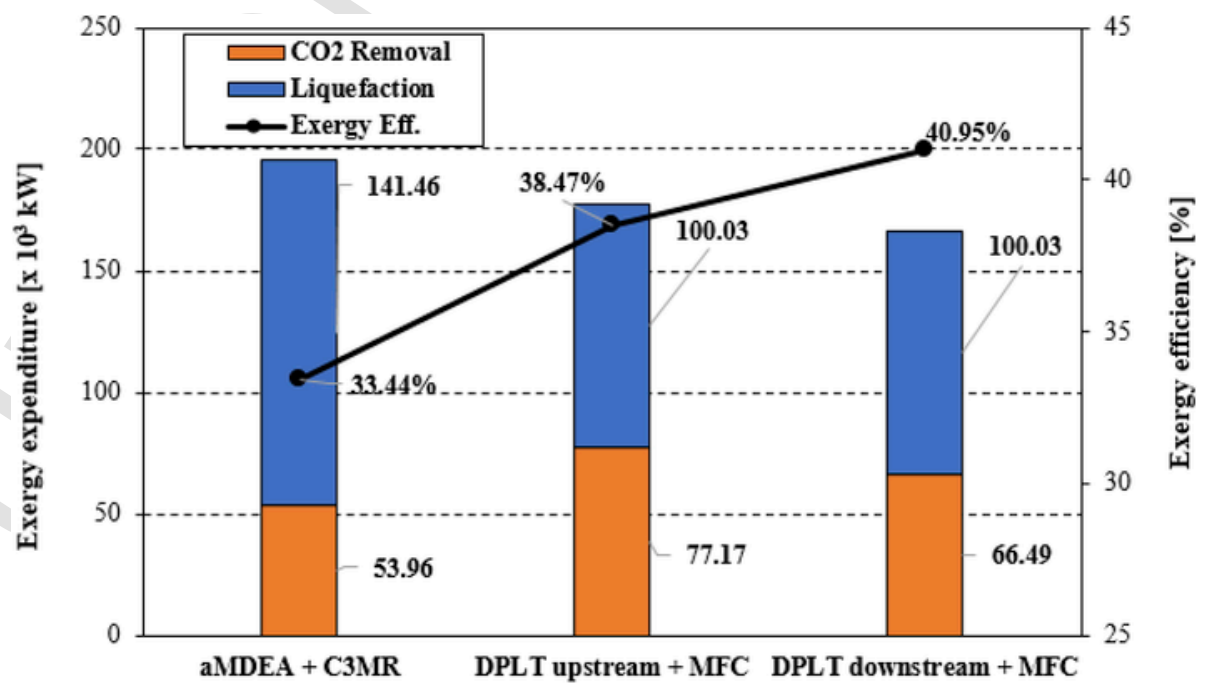

Fig. 20. Exergy expenditure $\left[\mathrm{x} 10^{3} \mathrm{~kW}\right]$ and exergy efficiency [\%] of the different schemes considered for the overall LNG production chain, as specified in the figure. 
part of this work in Japan and Mr. Tsuneo Watanabe of Chiyoda Corporation, expert in LNG industry, for his insights and feedbacks.

\section{NOMENCLATURE}

$\begin{array}{ll}\text { Abbreviations } \\ \text { AGRU } & \text { Acid Gas Removal Unit } \\ \text { aMDEA } & \text { activated MethylDiethanolAmine } \\ \text { BOG } & \text { Boil-Off-Gas } \\ \text { C3MR } & \text { Propane mixed refrigerant } \\ \text { DPLT } & \text { Dual Pressure Low-Temperature } \\ \text { EOR } & \text { Enhanced Oil Recovery } \\ \text { EoS } & \text { Equation of State } \\ \text { Ex } & \text { Exergy } \\ \text { Eff } & \text { Efficiency } \\ \text { HCs } & \text { Hydrocarbons } \\ \text { HE } & \text { Heat exchanger } \\ \text { HP } & \text { High-pressure } \\ \text { LNG } & \text { Liquefied Natural Gas } \\ \text { LP } & \text { Low-pressure } \\ \text { MCHE } & \text { Main Cryogenic Heat Exchanger } \\ \text { MFC } & \text { Mixed Fluid Cascade } \\ \text { MR } & \text { Mixed refrigerant } \\ \text { NG } & \text { Natural gas } \\ \text { NGLs } & \text { Natural Gas Liquids } \\ \text { PZ } & \text { Piperazine } \\ \text { SLVE } & \text { Solid-Liquid-Vapor equilibrium } \\ \text { SMR } & \text { Single Mixed Refrigerant } \\ \text { SMC } & \text { Specific equivalent methane consumption }\left[\mathrm{kg}_{\mathrm{CH} 4, \mathrm{eq} .} / \mathrm{kg}_{\mathrm{CH} 4 \text {,in }}\right] \\ \text { SRK } & \text { Soave-Redlich-Kwong }\end{array}$

Symbols

$\dot{m}_{\mathrm{CH} 4} \quad$ Equivalent methane flowrate $[\mathrm{kg} / \mathrm{s}]$

$\dot{W} \quad$ Work flow $[\mathrm{kW}]$

$\dot{Q} \quad$ Heat flow $[\mathrm{kW}]$

$\eta_{B} \quad$ Efficiency of boiler

$\eta_{C C} \quad$ Efficiency of combined cycle power plant

$\eta_{\text {ex }} \quad$ Exergy efficiency

$\eta_{\text {II }} \quad$ Thermodynamic second law efficiency

$L H V_{C H 4}$ Lower Heating Value of methane $[\mathrm{kJ} / \mathrm{kg}]$

$T_{i} \quad$ Temperature $[\mathrm{K}]$ at which the heat flow $\dot{Q}_{i}$ is exchanged

$T_{0} \quad$ Temperature $[\mathrm{K}]$ at reference environmental conditions

$P_{0} \quad$ Pressure at reference environmental conditions [bar]

$\tau_{i} \quad$ Carnot factor

$R \quad$ Gas constant $[\mathrm{J} /(\mathrm{mol} \mathrm{K})]$

$\dot{E} x^{W} \quad$ Exergy of work interactions [kW]

$\dot{E} x^{Q} \quad$ Exergy of heat interactions [kW]

$\dot{E} x^{\text {mat }} \quad$ Exergy of material streams $[\mathrm{kW}]$

$\dot{N}_{i} \quad$ Molar flow rate of $i$-th stream $[\mathrm{kmol} / \mathrm{s}]$

ex ${ }_{\text {mixt,i }}^{P h} \quad$ Molar physical exergy of $i$-th stream [J/mol)]

$\mathrm{ex}_{\text {mixt } \mathrm{Ch}}^{\mathrm{Ch}, i} \quad$ Molar chemical exergy of $i$-th stream $[\mathrm{J} / \mathrm{mol}]$

$h_{i} \quad$ Molar enthalpy of $i$-th stream $[\mathrm{J} / \mathrm{mol}]$

$s_{i} \quad$ Molar entropy of $i$-th stream $[\mathrm{J} /(\mathrm{mol} \mathrm{K})]$

$h_{0 i} \quad$ Molar enthalpy of $i$-th stream at reference temperature and pressure $[\mathrm{J} / \mathrm{mol}]$

$s_{0 i} \quad$ Molar entropy of $i$-th stream at reference temperature and pressure $[\mathrm{J} /(\mathrm{mol} \mathrm{K})]$

$x_{j i} \quad$ Mole fraction of component $j$ in $i$-th mixture

ex $x_{\text {std } j}^{c h} \quad$ Molar chemical exergy of $j$-th component in the $i$-th stream at reference conditions $[\mathrm{J} / \mathrm{mol}]$

$\gamma_{i} \quad$ Activity coefficient of $i$-th stream

\section{Appendix A. Supplementary data}

Supplementary data to this article can be found online at https:// doi.org/10.1016/j.jngse.2018.11.016.

\section{References}

Alvis, R.S., Hatcher, N.A., Weiland, R.H., 2012. $\mathrm{CO}_{2}$ removal from syngas using piperazine-activated MDEA and potassium dimethyl glycinate. Nitrogen + Syngas 2012.

Amin, R., Jackson, A.T., Kennaird, T., 2005. The Cryocell: an advanced gas sweetening technology. In: International Petroleum Technology Conference, International Petroleum Technology Conference, Doha, Qatar.

AspenTech, 2017. Aspen HYSYS®. AspenTech, Burlington, MA, United States.

Association, N.G.S. (Ed.), 2013. Overview of Natural Gas: Background.

Baccanelli, M., Langé, S., Rocco, M.V., Pellegrini, L.A., Colombo, E., 2016. Low temperature techniques for natural gas purification and LNG production: an energy and exergy analysis. Appl. Energy 180, 546-559.

Bagirov, L.A., Imaev, S.Z., Borisov, V.E., 2015. R\&D technologies for acid gases extraction from natural gases. In: SPE/IATMI Asia Pacific Oil \& Gas Conference and Exhibition. Society of Petroleum Engineers.

Bakshi, B.R., Gutowski, T.G., Sekulic, D.P., 2011. Thermodynamics and the Destruction of Resources. Cambridge University Press.

Boschee, P., 2014. Taking on the Technical Challenges of Sour Gas Processing. https:// www.spe.org/en/print-article/?art $=51$, Las accessed on July 2018

CleaverBrooks Inc., Boiler Efficiency Guide-facts about Firetube Boilers and Boiler Efficiency, 2011. Cleaver-Brooks, Inc., Thomasville, GA, USA.

Clodic, D., Younes, M., 2003. A new method for $\mathrm{CO}_{2}$ capture: frosting $\mathrm{CO}_{2}$ at atmospheric pressure. In: Greenhouse Gas Control Technologies-6th International Conference. Elsevier, pp. 155-160.

Darman, N., Harun, A., 2006. Technical challenges and solutions on natural gas development in Malaysia. In: The Petroleum Policy and Management Project, 4th Workshop of the China-Sichuan Basin Study, Beijing, China.

De Guido, G., Langè, S., Moioli, S., Pellegrini, L.A., 2014. Thermodynamic method for the prediction of solid $\mathrm{CO}_{2}$ formation from multicomponent mixtures. Process Saf. Environ. Protect. 92, 70-79.

De Guido, G., Langè, S., Pellegrini, L.A., 2015. Refrigeration cycles in low-temperature distillation processes for the purification of natural gas. J. Nat. Gas Sci. Eng. 27, 887-900.

De Guido, G., Fogli, M.R., Pellegrini, L.A., 2018. Effect of heavy hydrocarbons on $\mathrm{CO}_{2}$ removal from natural gas by low-temperature distillation. Ind. Eng. Chem. Res. 57, 7245-7256.

DITEC Università degli Studi di Genova, Elementi di Analisi Exergetica.

Dyment, J., Watanasiri, S., 2015. Acid Gas Cleaning Using DEPG Physical Solvents: Validation with Experimental and Plant Data. Aspen Technology Inc., The USA.

Gaumer, L., Newton, C., 1973. Combined Cascade and Multicomponent Refrigeration System and Method, Patent US4404008A.

Hart, A., Gnanendran, N., 2009. Cryogenic $\mathrm{CO}_{2}$ capture in natural gas. Energy Procedia 1 , 697-706.

Haut, R., Thomas, E., 1989. Development and application of the controlled-freeze-zone process. SPE Prod. Eng. 4, 265-271.

Holmes, A.S., Ryan, J.M., 1982. Cryogenic Distillative Separation of Acid Gases from Methane, Patent US4318723 A.

Holmes, A., Ryan, J., 1982. Distillative Separation of Carbon Dioxide from Light Hydrocarbons, Patent US4350511 A.

Holmes, A., Price, B., Ryan, J., Styring, R., 1983. Pilot tests prove out cryogenic acid-gas/ hydrocarbon separation processes. Oil Gas J. 81, United States.

Jaya, A., 2013. In: LNG UNIT (ENGINEERING DESIGN GUIDELINE). KLM Technology Group, Johor Bahru, p. 60.

Kehlhofer, R., Hannemann, F., Rukes, B., Stirnimann, F., 2009. Combined-cycle Gas \& Steam Turbine Power Plants, third ed. Pennwell Books, Tulsa, Oklahoma, USA

Khan, M.S., Lee, S., Rangaiah, G., Lee, M., 2013. Knowledge based decision making method for the selection of mixed refrigerant systems for energy efficient LNG processes. Appl. Energy 111, 1018-1031.

Khan, M.S., Karimi, I., Bahadori, A., Lee, M., 2015. Sequential coordinate random search for optimal operation of LNG (liquefied natural gas) plant. Energy 89, 757-767.

Kidnay, A.J., Parrish, W.R., McCartney, D.G., 2011. Fundamentals of Natural Gas Processing. CRC Press.

Kohl, A.L., Nielsen, R., 1997. Gas Purification. Gulf Professional Publishing.

Kotas, T.J., 2013. The Exergy Method of Thermal Plant Analysis. Elsevier.

Lallemand, F., Lecomte, F., Streicher, C., 2005. Highly sour gas processing: $\mathrm{H}_{2} \mathrm{~S}$ bulk removal with the Sprex process. In: International Petroleum Technology Conference, International Petroleum Technology Conference, Doha, Qatar.

Lallemand, F., Perdu, G., Normand, L., Weiss, C., Magne-Drisch, J., Gonnard, S., 2014. Extending the treatment of highly sour gases: cryogenic distillation. Petrol. Technol. Q. $19,55-61$.

Langè, S., Pellegrini, L.A., Vergani, P., Lo Savio, M., 2015. Energy and economic analysis of a new low-temperature distillation process for the upgrading of high- $\mathrm{CO}_{2}$ content natural gas streams. Ind. Eng. Chem. Res. 54, 9770-9782.

Maher, J.B., Sudduth, J.W., 1975. Method and Apparatus for Liquefying Gases, Patent US3914949A.

Maqsood, K., Mullick, A., Ali, A., Kargupta, K., Ganguly, S., 2014. Cryogenic carbon dioxide separation from natural gas: a review based on conventional and novel emerging technologies. Rev. Chem. Eng. 30, 453-477.

Marmolejo-Correa, D., Gundersen, T., 2012. A comparison of exergy efficiency definitions with focus on low temperature processes. Energy 44, 477-489. 
Mazzoccoli, M., De Guido, G., Bosio, B., Arato, E., Pellegrini, L.A., 2013. $\mathrm{CO}_{2}$-mixture properties for pipeline transportation in the CCS process. Chemical Engineering Transactions 32, 1861-1866.

Mokhatab, S., Mak, J.Y., Valappil, J.V., Wood, D.A., 2013. Handbook of Liquefied Natural Gas. Gulf Professional Publishing.

Northrop, P.S., Valencia, J.A., 2009. The CFZ ${ }^{\mathrm{TM}}$ process: a cryogenic method for handling high- $\mathrm{CO}_{2}$ and $\mathrm{H}_{2} \mathrm{~S}$ gas reserves and facilitating geosequestration of $\mathrm{CO}_{2}$ and acid gases. Energy Procedia 1, 171-177.

Parker, P.M.E., Northrop, S., Valencia, J.A., Foglesong, R.E., Duncan, W.T., 2011. $\mathrm{CO}_{2}$ management at ExxonMobil's LaBarge field, Wyoming, USA. Energy Procedia 4, 5455-5470.

Pellegrini, L.A., 2014. Process for the Removal of CO2 from Acid Gas, Patent US14432726.

Pellegrini, L.A., Moioli, S., Brignoli, F., Bellini, C., Technology, L.N.G., 2014. The weathering in above-ground storage tanks. Ind. Eng. Chem. Res. 53, 3931-3937.

Pellegrini, L.A., De Guido, G., Consonni, S., Bortoluzzi, G., Gatti, M., 2015. From biogas to biomethane: how the biogas source influences the purification costs. Chemical Engineering Transactions 43, 409-414.

Pellegrini, L.A., Langé, S., De Guido, G., Moioli, S., Mikus, O., Picutti, B., Vergani, P., Franzoni, G., Lo Savio, M., Brignoli, F., 2015. An innovative technology for natural gas sweetening by means of cryogenic distillation. In: GPA Europe Annual Conference, Florence, Italy.

Pellegrini, L.A., Langè, S., Baccanelli, M., De Guido, G., 2015. Techno-economic analysis of LNG production using cryogenic vs conventional techniques for natural gas purification. In: Offshore Mediterranean Conference and Exhibition, Offshore Mediterranean Conference, Ravenna, Italy.

Pellegrini, L.A., De Guido, G., Langè, S., Moioli, S., Picutti, B., Vergani, P., Franzoni, G., Brignoli, F., 2016. The potential of a new distillation process for the upgrading of acid gas. In: Abu Dhabi International Petroleum Exhibition \& Conference (ADIPEC). Society of Petroleum Engineers, Abu Dhabi, UAE.

Pellegrini, L.A., De Guido, G., Lodi, G., Mokhatab, S., 2017. $\mathrm{CO}_{2}$ capture from natural gas in LNG production. Comparison of low-temperature purification processes and conventional amine scrubbing. In: Cutting Edge for Carbon Capture Utilization and Storage, pp. 283-308.

Pellegrini, L.A., De Guido, G., Langé, S., 2017. Biogas to liquefied biomethane via cryogenic upgrading technologies. Renew. Energy 124, 75-83.

Pettersen, J., 2012. LNG plant overview. In: Seminar with Supplier Association Murmanshelf Murmansk.
Poling, B.E., Prausnitz, J.M., John Paul, O.C., Reid, R.C., 2001. The Properties of Gases and Liquids. Mcgraw-hill, New York.

Querol, E., Gonzalez-Regueral, B., Perez-Benedito, J.L., 2012. Practical Approach to Exergy and Thermoeconomic Analyses of Industrial Processes. Springer Science \& Business Media, New York, NY, USA.

Querol, E., Gonzalez-Regueral, B., Perez-Benedito, J.L., 2013. Exergy concept and determination. In: Practical Approach to Exergy and Thermoeconomic Analyses of Industrial Processes. Springer, pp. 9-28.

Rojey, A., Jaffret, C., 1997. Natural Gas: Production, Processing, Transport. Editions Technip.

Scherbinin, A., May, 2012. Shell experience in sour gas fields. In: Turkmenistan Gas Conference, Proceedings of the Turkmenistan Gas Conference, Avaza, Turkmenistan. pp. 23-24.

Sciubba, E., Wall, G., 2007. A brief commented history of exergy from the beginnings to 2004. Int. J. Therm. 10, 1-26.

Shimekit, B., Mukhtar, H., 2012. Natural gas purification technologies-major advances for $\mathrm{CO}_{2}$ separation and future directions. In: Advances in Natural Gas Technology. InTech.

Smith, R., 2005. Chemical Process: Design and Integration. John Wiley \& Sons.

Soave, G., 1972. Equilibrium constants from a modified Redlich-Kwong equation of state. Chem. Eng. Sci. 27, 1197-1203.

Soave, G.S., Gamba, S., Pellegrini, L.A., Bonomi, S., 2006. Feed-splitting technique in cryogenic distillation. Ind. Eng. Chem. Res. 45, 5761-5765.

Stockmann, R., Forg, W., Bolt, M., Steinbauer, M., Pfeiffer, C., Paurola, P., Fredheim, A.O., Sorensen, O., 2001. Method for Liquefying a Stream Rich in Hydrocarbons, Patent US6253574B1.

Szargut, J., 2005. Exergy Method: Technical and Ecological Applications. WIT press.

U.S.Energy Information Administration (EIA), 2017. International Energy Outlook Executive Summary.

Valencia, J.A., Denton, R.D., 1985. Method and Apparatus for Separating Carbon Dioxide and Other Acid Gases from Methane by the Use of Distillation and a Controlled Freezing Zone, Patent US 4,533,372.

Valencia, J.A., Victory, D.J., 1990. Method and Apparatus for Cryogenic Separation of Carbon Dioxide and Other Acid Gases from Methane, Patent US 4923493A.

Vatani, A., Mehrpooya, M., Palizdar, A., 2014. Energy and exergy analyses of five conventional liquefied natural gas processes. Int. J. Energy Res. 38, 1843-1863.

Venkatarathnam, G., Timmerhaus, K., 2008. Cryogenic Mixed Refrigerant Processes. Springer. 